Universidade de São Paulo

FFCLRP - Departamento de Física

Pós-Graduação em Física Aplicada à Medicina e Biologia

ANTONIO CARLOS NUNES BERTOLO

\title{
Avaliação do Desempenho de um Sistema de Tomografia PET com Geometria Elipsoidal.
}

Ribeirão Preto - SP 


\title{
ANTONIO CARLOS NUNES BERTOLO
}

\section{Avaliação do Desempenho de um Sistema de Tomografia PET com Geometria Elipsoidal.}

Dissertação apresentada à Faculdade de Filosofia, Ciências e Letras de Ribeirão Preto da Universidade de São Paulo, como parte das exigências para obtenção do título de Mestre em Ciências.

Área de Concentração: Física Aplicada à Medicina e Biologia.

Orientador: Prof. Dr. Eder Rezende Moraes

\author{
Versão original \\ Disponível na FFCLRP - USP
}

Ribeirão Preto - SP 
Autorizo a reprodução e divulgação total ou parcial deste trabalho, por qualquer meio convencional ou eletrônico, para fins de estudo e pesquisa, desde que citada a fonte.

\section{FICHA CATALOGRÁFICA}

Bertolo, Antonio Carlos Nunes

Avaliação do Desempenho de um Sistema de Tomografia PET com Geometria Elipsoidal / Antonio Carlos Nunes Bertolo; orientador Eder Rezende Moraes. Ribeirão Preto - SP, 2014.

72 f.:Il.

Dissertação (Mestrado - Programa de Pós-Graduação em Física Aplicada à Medicina e Biologia) - Faculdade de Filosofia Ciências e Letras de Ribeirão Preto da universidade de São Paulo, 2014.

1. Tomografia por Emissão de Pósitrons. 2. Sistema PET elíptico. 3. Sensibilidade do PET. 4. NEC e Resolução Espacial. 
Nome: Bertolo, Antonio Carlos Nunes

Título: Avaliação do Desempenho de um Sistema de Tomografia PET com Geometria Elipsoidal.

Dissertação apresentada à Faculdade de Filosofia, Ciências e Letras de Ribeirão Preto da Universidade de São Paulo, como parte das exigências para obtenção do título de Mestre em Ciências.

Aprovado em:

Banca Examinadora

$\operatorname{Prof}(\mathrm{a}) \cdot \operatorname{Dr}(\mathrm{a})$ : : Instituição:

Julgamento: Assinatura:

$\operatorname{Prof(a).~Dr(a).~:~}$ Instituição:

Julgamento: Assinatura:

Prof(a). Dr(a). : Instituição: Assinatura: 
Aos meus pais Solange e Bertolo por todo amor, confiança, auxílio, carinho e dedicação em todos os momentos da minha vida. 


\section{Agradecimentos}

A Deus pelo dom da vida, por toda provisão e sustento, por cada oportunidade e pelas portas que me abriu;

Ao professor Eder pela oportunidade, orientação, ensinamentos, paciência, confiança etc;

Ao meu irmão Eduardo, cunhada Carla, meus sobrinhos João Vitor e Davi pela confiança e apoio;

A minha noiva Ana Carolina e sua filha Ana Laura pelo amor, carinho, confiança e paciência;

A minha filha Sara pela inspiração e por todo amor que nem mesmo a distância pode afetar;

A minha família pela confiança e apoio;

A INSEJEC-Avaré, meus pastores Vicente e Iara e ao ministério de louvor Nova Jornada pelas orações, apoio e conversas;

Aos colegas do GIMN e de pós-graduação pela ajuda e discussões que muito contribuíram para minha formação;

A todos que de alguma forma me ajudaram ao longo do mestrado;

A CAPES pelo apoio financeiro. 


\section{RESUMO}

\section{BERTOLO, A.C.N. Avaliação do desempenho de um sistema de tomografia PET com}

geometria elipsoidal. $2014.72 \mathrm{f}$.

Dissertação de Mestrado - Programa de Pós-graduação em Física Aplicada à Medicina e Biologia).

Faculdade de Filosofia, Ciências e Letras de Ribeirão Preto, Universidade de São Paulo, Ribeirão Preto-SP, 2014.

Dentre as técnicas diagnósticas por imagem, em Medicina Nuclear, têm-se destacado a Tomografia por Emissão de Pósitrons (PET). O PET fornece imagens funcionais da região ou órgão de interesse, possibilitanto o diagnóstico de várias doenças e, também, um mapeamento da evolução ou regressão das mesmas. Os atuais sistemas PET apresentam blocos de cristais arranjados em geometria circular, mas a busca por novos arranjos, em geometrias diferenciadas, é pertinente, pois pode possibilitar um melhor desempenho destes tomógrafos.

O objetivo deste estudo é avaliar o desempenho de um sistema PET constituído por blocos de cristais em arranjo elipsoidal.

Para tal estudo, fez-se uso do GATE, ambiente de simulação para tomografia por emissão que apresentou resultados satisfatórios comparados à aparelhos utilizados na rotina clínica. Desta forma, elaborou-se dois sistemas PET, o primeiro com 46 blocos de cristais arranjados em geometria circular, no qual, os detectores opostos foram separados a uma distância de 816,4 mm na direção transaxial. No segundo caso, utilizou-se 36 blocos de cristais, arranjados em geometria elíptica, onde os detectores foram separados a uma distância de 500 mm na direção vertical e 816,4 mm na direção horizontal.

Uma vez realizadas as simulações, fez-se os testes de validação para Sensibilidade, Fração de Espalhamento, NEC (Noise Equivalente Count Rate) e Resolução Espacial, para então, avaliar e comparar o desempenho do sistema PET para ambas as geometrias propostas. Estes testes foram feitos de acordo com as especificações da norma NEMA NU 2-2007. 
Para o teste de sensibilidade, com o phantom localizado no centro do FOV transaxial do tomógrafo, obteve-se um ganho no sistema PET, com geometria elíptica, de 28,7\% em relação ao sistema convencional, de geometria circular. Para o phantom deslocado à $10 \mathrm{~cm}$ do centro do FOV transaxial, a sensibilidade do sistema PET elíptico foi $26,2 \%$ superior em relação ao circular. O tempo de aquisição para cada simulação neste teste foi de $400 \mathrm{~s}$.

Para os testes de Fração de Espalhamento e NEC foram realizadas 33 simulações, para cada geometria, variando o tempo de aquisição e a atividade. A fração de espalhamento na geometria elíptica foi de $35,5 \%$ e na circular $34,6 \%$.

Na geometria circular, a curva NEC atinge o pico máximo em 259,3 kcps a uma concentração de atividade de $34,1 \mathrm{kBq} \mathrm{ml}^{-1}$, já para geometria elíptica, o pico máximo é atingido em 239,1 kcps a uma concentração de atividade de $24,8 \mathrm{kBq} \mathrm{ml}^{-1}$.

As medidas foram adquiridas em três posições transaxiais $(\mathrm{x}, \mathrm{y})$ no centro do FOV e, posteriormente, deslocadas em $1 / 4$ do centro do FOV, totalizando 6 medidas para cada geometria. Para cada uma destas 6 medidas, encontrou-se a FWHM (largura a meia altura) e a FWTM (largura a 10\% do máximo) nos 3 eixos de coordenadas (x,y,z), assim, para cada geometria proposta obteve-se 18 valores de FWHM e 18 valores de FWTM.

A geometria elíptica apresentou melhoras na resolução espacial em FWHM em 4 dos 18 valores de resolução. Já para FWTM, a geometria elíptica apresentou melhora em 8 dos 18 valores de resolução. Em relação a FWHM, onde houve melhora na resolução espacial, tevese um ganho médio de 18,7\%. Já as perdas, em resolução espacial foi em média 43,26\%. Para FWTM, a melhora em resolução espacial foi em média 12,09\%, mas a perda de resolução, neste caso, foi em média 45,59\%.

Pode-se concluir que a geometria proposta apresenta algumas vantagens em relação a geometria convencional. Na geometria elíptica há uma redução de 10 blocos de cristais em relação a geometria circular, o que possivelmente gera uma redução no custo de fabricação do tomógrafo. Em relação a sensibilidade, há uma melhora significativa para nova geometria, bem como uma redução da concentração da atividade na qual o tomógrafo alcança seu melhor desempenho, embora ocorra uma ligeira diminuição na taxa de contagens no sistema elíptico. Essa redução na concentração de atividade pode ocasionar uma redução no tempo de exame e utilização de menos material radioativo, reduzindo o risco ao paciente e o custo do exame, bem como possibilitando a realização de um maior número de exames num mesmo intervalo 
de tempo. A fração de espalhamento do sistema elíptico é ligeiramente maior em relação ao sistema circular.

A principal perda do sistema PET elíptico está na resolução espacial, onde não houve melhoras para maior parte das medidas realizadas, necessitando de alguns ajustes que pode se dar, entre outras coisas, no arranjo dos blocos de cristais. Acredita-se que ajustes na angulação dos detectores e na formação das coincidências seja possível melhorias nas resoluções, e NEC.

Palavras-chave: Tomografia por Emissão de Pósitrons, sistema PET elíptico, Sensibilidade do PET, NECR e Resolução Espacial. 


\begin{abstract}
BERTOLO, A.C.N. Performance evaluation of a system for PET tomography ellipsoidal geometry. 2014. $72 \mathrm{f}$.

Dissertation (MSc.- Postgraduate program in Physics applied to Medicine and Biology).

Faculty of Philosophy, Sciences and Literature, University of São Paulo, Ribeirão Preto-SP, 2014.
\end{abstract}

Among the diagnostic imaging techniques, in Nuclear Medicine, have been prominent in Positron Emission Tomography (PET). PET provides functional images of the region or organ of interest, allowing diagnostic of various diseases and also a mapping of the development or regression of the same. Current PET systems feature blocks arranged in circular geometry crystals, but the search for new arrangements, in different geometries, is relevant because it can provide a better performance of these scanners.

The objective of this study is to evaluate the performance of a PET system consisting of blocks of crystals ellipsoidal arrangement.

For this study, we used the GATE simulation environment for emission tomography that presented satisfactory results compared to the devices used in the clinical routine. This way we prepared two PET systems, the first one containing 46 blocks of crystals arranged in a circular geometry, where the opposite detectors were separated by a distance of $816.4 \mathrm{~mm}$ in the transaxial direction.

In the second case, we used 36 blocks of crystals arranged in an elliptical geometry, where the detectors are separated a distance of $500 \mathrm{~mm}$ in the vertical direction and $816.4 \mathrm{~mm}$ in the horizontal direction.

After the simulations were performed, the validation tests for sensitivity, scatter fraction, NEC (Noise Equivalent Count Rate) and Spatial Resolution were made, to finally evaluate and compare the performance of the PET system for both proposed geometries.

The tests were made accordingly to specified NEMA NU 2-2007 standard. 
For the sensitivity test, with the phantom located in the center of FOV transaxial of the tomography, we obtained a gain in PET system with elliptical geometry of $28.7 \%$ compared to the conventional system, the circular geometry. For the phantom shifted to $10 \mathrm{~cm}$ from the center of the transaxial FOV, the sensitivity of PET elliptical system was $26.2 \%$ higher than in the circular. The acquisition time for each simulation in this test was $400 \mathrm{~s}$.

For Scatter Fraction test and NEC, were made 33 simulations for each geometry, varying the time of acquisition and activity. The scatter fraction in the elliptical geometry was $35,5 \%$ and $34,6 \%$ in the circular geometry.

In the circular geometry, NEC curve reaches its peak in $259.3 \mathrm{kcps}$ at an activity concentration of $34.1 \mathrm{kBq} \mathrm{ml}^{-1}$, for the elliptical geometry, the maximum peak is reached at $239.1 \mathrm{kcps}$ at an activity concentration of $24.8 \mathrm{kBq} \mathrm{ml}^{-1}$.

For the spatial resolution test we used a point source containing $18 \mathrm{~F}$ with $4 \mathrm{MBq}$ activity and acquisition time of $200 \mathrm{~s}$. The measurements were acquired in three transaxials positions $(\mathrm{x}, \mathrm{y})$ in the center of FOV and, shifted in $1 / 4$ of the center of the FOV, summarizing 6 measurements for each geometry. For each one of these 6 measurements, we found the FWHM (Full width at half-maximum amplitude) and the FWTM (Full width at tenthmaximum amplitude) in the three axis $(\mathrm{x}, \mathrm{y}, \mathrm{z})$, in this way, for each proposed geometry, we obtained 18 values of FWHM and 18 values of FWTM.

The elliptical geometry showed improvement in the spatial resolution in FWHM in 4 of the 18 resolution values. For the FWTM, the elliptical geometry showed improvement in 8 of 18 resolution values. Regarding the FWHM, where there was an improvement in spatial resolution, we obtained the average gain of $18,7 \%$. For the losses, in spatial resolution was an average of $43,26 \%$. For the FWTM, the improvement in spatial resolution was an average percentage of $12,09 \%$, while the loss of resolution had the average percentage of $45,59 \%$.

It can be concluded that the proposed geometry showed some advantages regarding the traditional geometry. In the elliptical geometry there is one reduction of 10 blocks of crystals in relation to the circular geometry, which possibly can cut fabrication costs of the tomography. Regarding to sensibility, there is a significant improvement for the new geometry, as well as one reduction of the activity concentration in which the tomography reaches the best performance, although the occurrence of a slight fall in the counts in the elliptical system. 
This reduction in the activity concentration can help to reduce the test time and the use less radioactive material, reducing the risk for the patients and the test costs, as well as improving the number of tests in the same period of time. The scattering fraction in the elliptical system is slight higher to the circular system.

The major loss in the elliptical PET system is the spatial resolution, where there was not improvement for the great fraction of the obtained measurements, requiring some modifications that can be made, in special, in the crystal blocks arrangement. It is believed that some modifications to the angle of the detectors and in the formation of the coincidences can improve the resolutions and NEC.

Key-words: Positron Emission Tomography, Eliptical PET system, Sensitivity of PET, NECR and Spatial Resolution. 


\section{Lista de Figuras}

Figura 1: Aniquilação elétron-pósitron. Imagem adaptada de Physics in Nuclear Medicine, $4^{\mathrm{a}}$ Edição (Cherry, S. R., et al).

Figura 2: Respresentação da TOR e LOR entre 2 blocos de detectores. Adaptado de Optimal and Robust PET Data SinogramRestauration Based on the Response of the System (Herraiz, J.L.; et al).

Figura 3: Campo de visão transaxial do PET definido pelo ângulo de aceitação do sistema. Adaptado do livro Positron Emission Tomography (Dale L. Bailey, et al).

Figura 4: Eventos de coincidências em Sistemas PET. Adaptado do livro Positron Emission Tomography (Dale L. Bailey, et al).

Figura 5: Comparação do comportamento de vários tipos de processamentos disponíveis para várias situações de múltiplas coincidências. As estrelas representam os singles detectados. O tamanho da estrela, bem como o número ao lado, indica o nível de energia do single (por exemplo: o single $\mathrm{n}^{\circ} 1$ tem maior energia que o single $\mathrm{n}^{\mathrm{o}} 2$, que por sua vez, tem maior energia que o single $n^{\circ} 3$ ). As linhas representam as possíveis coincidências. Figura adaptada de OpenGATEcollaboration: [www.opengatecollaboration.org] .......................................................... 11

Figura 6: Esquema de aquisição de dados 2D e 3D para sistemas PET. Imagem adaptada de Physics in Nuclear Medicine, $4^{\text {a }}$ Edição (Cherry, S. R., et al). .14

Figura 7: Obtenção dos eventos de coincidências através de pulsos (singles) individuais[15]. Imagem adaptada de Emission Tomography: The Fundamentals of PET and SPECT, 180 p. (Miles N. Wernick and John N. Aarsvold).

Figura 8: Novo sistema de coordenadas $(\mathrm{r}, \mathrm{s})$ rotacionado pelo ângulo de rotação $\phi$ em relação ao sistema de coordenadas $(\mathrm{x}, \mathrm{y})$. Adaptado de Physics in Nuclear Medicine, $4^{\mathrm{a}}$ Edição (Cherry, S. R., et al).

Figura 9: Criação do sinograma 2D através de um conjunto de projeções $1 \mathrm{D}$ gerado à partir de uma fonte pontual. Cada linha corresponde a uma projeção individual e as sucessivas linhas representam sucessivos ângulos de projeções. Adaptado de Physics in Nuclear Medicine, $4^{\mathrm{a}}$ Edição (Cherry, S. R., et al). 17 
Figura 10: Representação da geometria e da coordenada de um sistema PET convencional. O ângulo azimutal $(\phi)$ é medido em torno do anel, enquanto o ângulo polar $(\theta)$ é medido entre os anéis. Imagem adaptada do livro Positron Emission Tomography (Dale L. Bailey, et al).

Figura 11: Representação do Michelograma para três diferentes modos de aquisições em um tomógrafo com oito anéis. Cada ponto no gráfico representa um plano de resposta definido entre dois conjuntos de detectores opostos (sinogramas). O gráfico a esquerda, o primeiro plano definido é o anel 0 em coincidência com o detector oposto no mesmo anel 0 , o anel 1 em coincidência com o anel 1 e assim por diante, para todos os anéis, totalizando 8 sinogramas. No gráfico do meio, os mesmos planos são adquiridos com a adição de um conjunto nos espaços entre os detectores, com diferença de \pm 1 anel (anel 0 com anel 1, anel 1 com anel 0 , etc). $O$ gráfico à direita mostra sistema de aquisição 3D em que cada conjunto de dados é armazenado separadamente (no total de 64 sinogramas).Imagem adaptada do livro Positron Emission Tomography (Dale L. Bailey, et al) 19

Figura 12: Representação de uma LOR entre os detectores da e db. As variáveis (s e $\phi$ ) do sinograma também estão representados na figura.Imagem adaptada do livro Positron Emission Tomography (Dale L. Bailey, et al).

Figura 13: Resolução espacial para um par de detectores em coincidência. A resolução espacial $\left(\mathrm{R}_{\mathrm{det}}\right)$ é determinada pela largura $(\mathrm{d})$ do detector. No plano médio, a FWHM é igual a d/2. Rdet varia conforme a fonte de aproxima do detector. Adaptado de Physics in Nuclear Medicine, $4^{\text {a }}$ Edição (Cherry, S. R., et al). ........ 21

Figura 14: Largura aparente (d') do detector onde d' aumenta com o aumento do deslocamento radial em sistemas PET convencional arranjados em forma circular. Imagem adaptada de Physics in Nuclear Medicine, $4^{\mathrm{a}}$ Edição (Cherry, S. R., et al)........... 22

Figura 15: Curvas referentes às taxas de contagens. São mostradas as curvas para coincidências verdadeiras, aleatórias e múltiplas. Também é apresentada a curva da taxa de contagem de ruído equivalente (NEC). Estes dados foram registrados no sistema PET CTI ECAT 953B usando um cilindro de $20 \mathrm{~cm}$ de diâmetro com ${ }^{11} \mathrm{C}$ preenchido com água. Imagem adaptada do livro Positron Emission Tomography (Dale L. Bailey, et al). 
Figura 16: Coberturas de alumínio para o teste de sensibilidade. Imagem retirada de "A method for measuring the absolute sensitivity of positron emission tomography

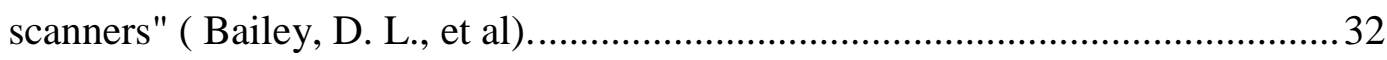

Figura 17: Representação das diferentes posições da fonte para as medidas de resolução espacial. Imagem adaptada de NEMA NU 2-2007. ........................................... 34

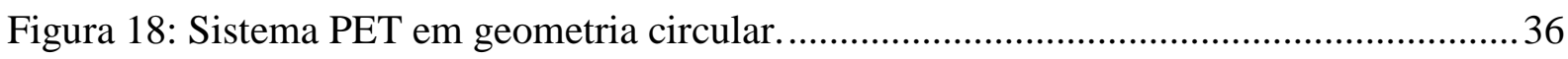

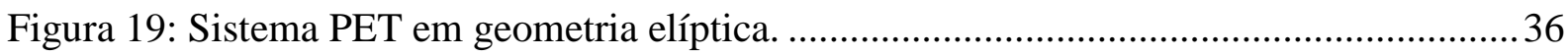

Figura 20: Sistema PET em geometria elíptica com os blocos posicionados com suas faces voltadas para o centro do FOV ................................................................... 37

Figura 21: Representação do sinograma obtido para o sistema PET cilíndrico. ...................... 38

Figura 22: Representação do sinograma obtido para o sistema PET elíptico. ......................... 38

Figura 23: Perfil de Sensibilidade para ambas as geometrias com as coberturas de alumínio localizadas no centro do sistema. A figura da esquerda representa a sensibilidade do sistema PET circular, enquanto a figura da direita representa a sensibilidade do

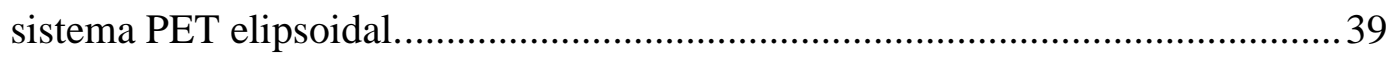

Figura 24: Perfil de Sensibilidade para ambas as geometrias com as coberturas de alumínio localizadas a $10 \mathrm{~cm}$ do sistema. A figura da esquerda representa a sensibilidade do sistema PET circular, enquanto a figura da direita representa a sensibilidade do

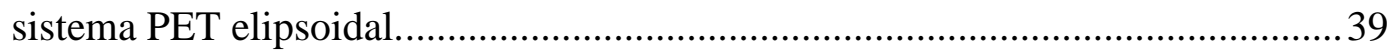

Figura 25: Comparação das curvas NEC para ambas as geometrias propostas. A curva rosa representa o sistema PET em geometria convencional e a curva vermelha representa o sistema PET em geometria diferenciada. 


\section{Lista de Tabelas}

Tabela 1: Alcance máximo do pósitron oriundo do decaimento do ${ }^{18} \mathrm{~F}$, cuja energia máxima é de $635 \mathrm{keV}$. O Alcance médio na água é de $0,06 \mathrm{~cm}$, ou 0,6 mm.

Tabela 2: Descrição dos vários tipos de coincidências múltiplas que podem ser implementadas no GATE. Quando uma coincidência múltipla, envolvendo n singles é processada, primeiramente é decomposta em uma lista de n(n-1) pares que são analisados individualmente. Nesta tabela o termo good (bom) significa que um par de singles estão em coincidência e que os dois singles são separados por um determinado número de blocos. O prefixo take significa que um ou mais pares de coincidências serão armazenados, enquento que o prefixo keep significa que uma única coincidência composta por pelo menos três singles será mantido no fluxo de dados e é conhecido por coincidências múltiplas. O prefixo kill significa que todos os eventos serão descartados e não produzirá nenhuma coincidência. Tabela adaptada de OpenGATEcollaboration: [www.opengatecollaboration.org].

Tabela 3: Tabela associada a figura 5. O sinal (-) significa que o evento é morto (nenhuma coincidência é formada. O sinal (*) indica que todos os singles são armazenados em uma única coincidência múltipla que não serão gravados nos discos, mas que podem influenciar na perda de dados através do tempo morto. Nestes outros casos, a lista dos pares que podem ser registrados (a não ser que sejam removidos posteriormente por um possível filtro aplicado as coincidências) é indicado. Tabela adaptada de OpenGATEcollaboration: [www.opengatecollaboration.org].

Tabela 4: Fórmulas para o cálculo da resolução espacial. Adaptada de NEMA NU 2-2007...28

Tabela 5: Medidas das coberturas de alumínio usadas para o teste de sensibilidade de acordo com NEMA NU 2-2007. Fonte (NEMA NU 2-2007).

Tabela 6: Valores dos tempos e atividades utilizados para os testes de Fração de Espalhamento e NECR. 35

Tabela 7: Valores da FWHM e FWTM na direção X. ( - ) Não foi possível obter valores em FWTM nesta posição.

Tabela 8: Valores da FWHM e FWTM na direção Y. 
Tabela 10: Resultado da resolução espacial para os sistemas PET cilíndrico e elíptico..........42

Tabela 11: Valores da FWHM e FWTM na direção X. ........................................................... 42

Tabela 12: Valores da FWHM e FWTM na direção Y........................................................... 43

Tabela 13: Valores da FWHM e FWTM na direção Z............................................................. 43

Tabela 14: Resultado da resolução espacial para os sistemas PET cilíndrico e elíptico, onde

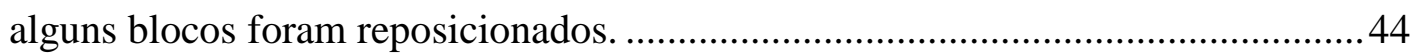




\section{Sumário}

1. Introdução

2. Fundamentos Teóricos.........................................................................................

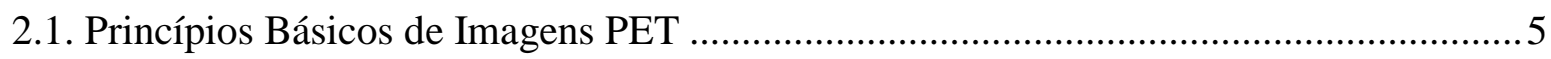

2.1.1. Detecção de Coicidências de Aniquilação. ................................................................

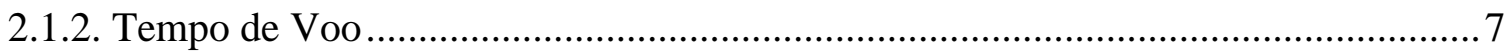

2.1.3. Tipos de eventos em Detectores de Coincidências de Aniquilação[14] ....................7

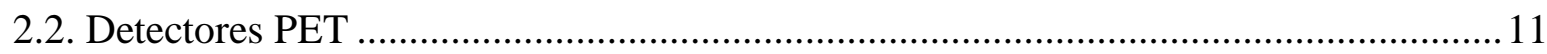

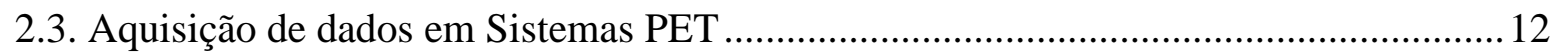

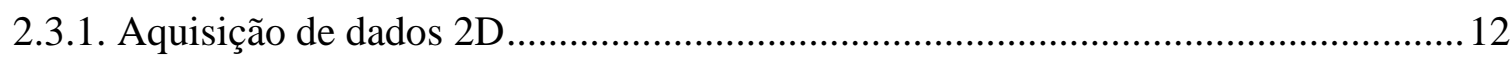

2.3.2.Aquisição de dados 3D....................................................................................... 13

2.4. Obtenção dos eventos de Coincidências [6] .................................................................. 14

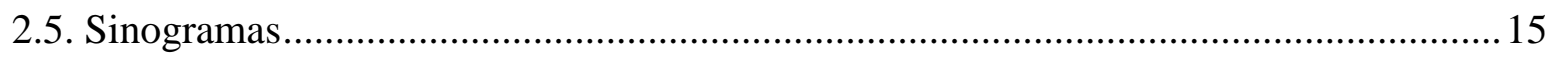

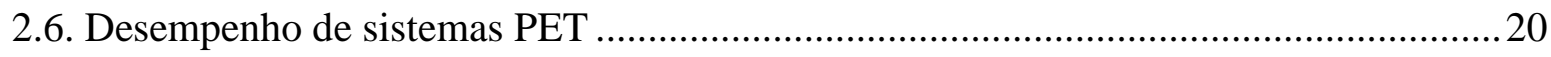

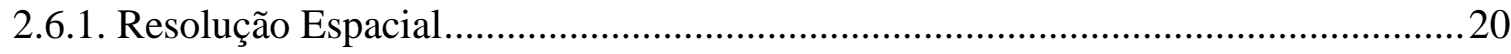

2.6.2. Taxa de Contagem de Ruído Equivalente (NEC) ………………...........................2 23

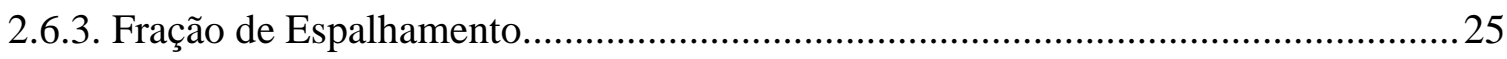

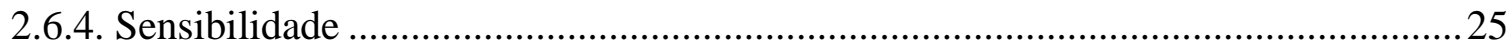

2.7. Norma NEMA NU 2-2007[8] ........................................................................... 27

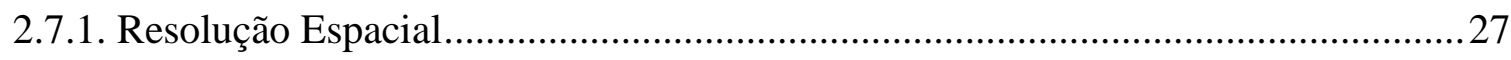

2.7.2. Fração de Espalhamento, perdas de contagens e medidas de aleatórios ...................28

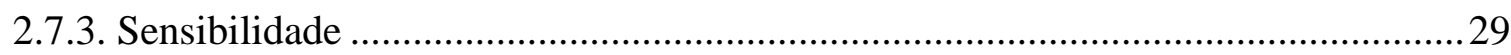

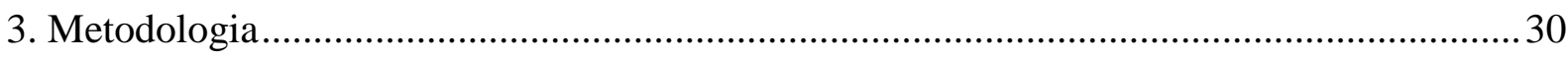

3.1. Construção da Geometria do Sistema PET ...................................................................... 30

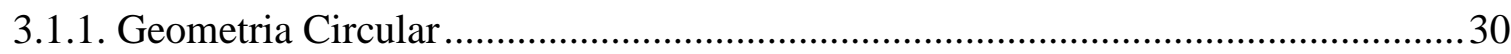

3.1.2. Geometria Elíptica........................................................................................... 31

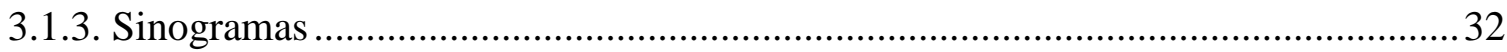

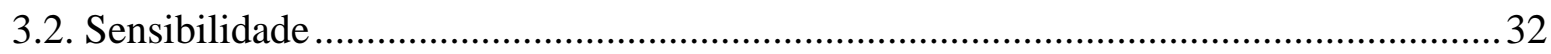

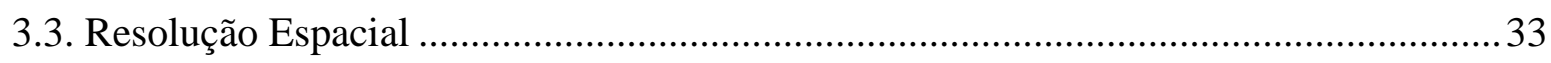

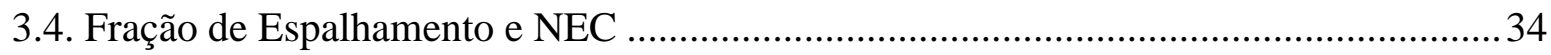

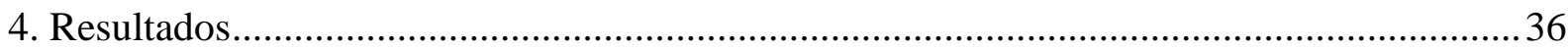




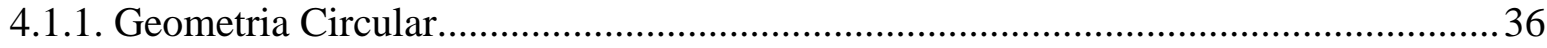

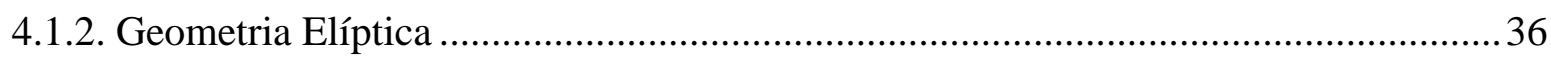

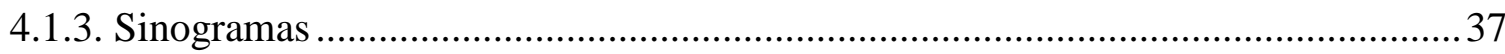

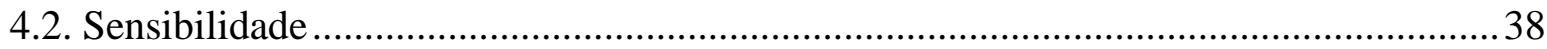

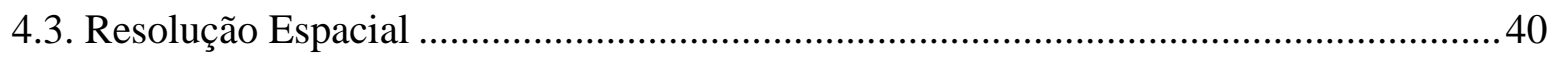

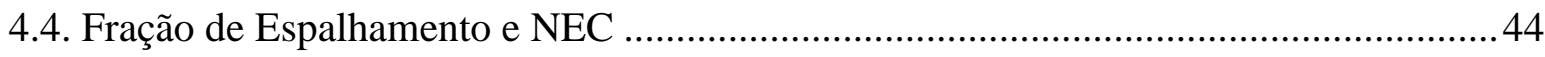

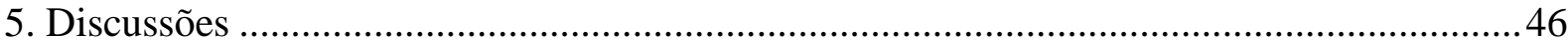

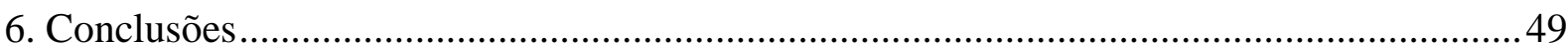

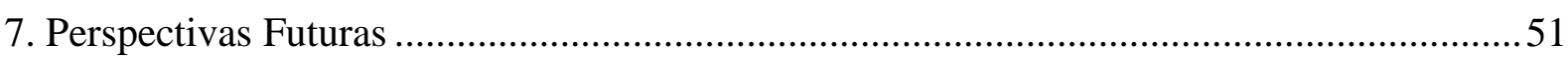

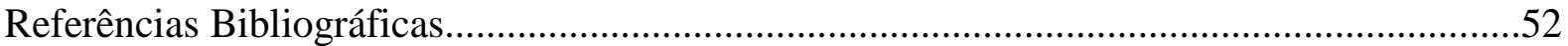




\section{Introducão}

Medicina Nuclear (MN) é uma especialidade médica que utiliza radioisótopos para fins diagnósticos e terapêuticos. Dentre as técnicas diagnósticas por imagem, em Medicina Nuclear, têm-se as imagens por emissão de fótons únicos, e por emissão de pósitrons. No primeiro caso, utiliza-se radiação eletromagnética de espectro amplo, em geral, aquela de maior intensidade de emissão pelo radionuclídeo utilizado. A técnica de imagens por emissão de pósitrons utiliza radioisótopos emissores de pósitrons, onde o pósitron se aniquila com um elétron próximo da sua região de emissão, produzindo dois fótons de aniquilação que são emitidos simultaneamente, em direções opostas e com mesma energia, uma vez que ocorre a conservação do momento neste processo. As imagens por emissão de pósitrons são obtidas através da detecção quase simultânea dos pares de fótons de aniquilação, com energia de 511 $\mathrm{keV}$ resultantes da aniquilação elétron-pósitron[1].

O emissor de pósitron mais utilizado para imagens por emissão de pósitrons é o Fluor$18\left({ }^{18} \mathrm{~F}\right)$, no qual, cerca de $97 \%$ dele decai emitindo pósitrons, que o torna amplamente vantajoso para este tipo de imagens médicas. $\mathrm{O}{ }^{18} \mathrm{~F}$ é usado para formar o FluorDesoxiGlicose (FDG), radiofármaco muito utilizado em imagens PET. Porém, sua curta meia-vida, em torno de 110 minutos, faz com que seu uso necessite ser feito em centros de imagens próximos ao seu local de produção ou com acesso facilitado para o transporte do mesmo.

Atualmente, os equipamentos PET, utilizam de forma integrada, as tomografias computadorizadas (CT), formando um sistema PET-CT, que permite a informação de imagens funcionais, vindas do PET e das imagens anatômicas, fornecidas pelo CT, o que possibilita um diagnóstico mais preciso.

Pesquisas atuais em sistemas PET têm sido focadas, entre outras coisas, em um sistema com amplo campo de visão axial (AFOV - acrônimo do inglês Axial Field Of View), capazes de realizar exames de corpo inteiro[2], sistemas PET-CT dedicados ao imageamento de mamas[3], etc.

Até o momento de desenvolvimento deste projeto, nada encontrou-se em relação a alteração da geometria nas quais os cristais estão arranjados em sistemas PET, tais como já ocorreu para sistemas de SPECT cardíacos[4]. Os sistemas PET atuais, em sua maioria, apresentam cristais arranjados em forma circular. Dado que o corpo humano não apresenta 
geometria circular, é perfeitamente aceitável buscar novos arranjos geométricos para os cristais com possível melhora na sensibilidade do sistema.

A simulação tem-se mostrado uma ferramenta muito importante no desenvolvimento de pesquisas em tomografia por emissão. Uma vez que, procedimentos experimentais realizados em tomógrafos seriam bastante trabalhosos, apresentariam custos elevados, além de grande complexidade, a simulação tornou-se uma ferramenta importante para o desenvolvimento de pesquisas atuais e também, destaca-se a grande confiabilidade que obtem-se através das simulações.

Dentre os ambientes de simulações utilizados para pesquisas em tomografias por emissão destaca-se o GATE, desenvolvido pelo grupo OpenGate desde 2001. O GATE foi criado inicialmente com o objetivo de desenvolver um código de simulação em medicina nuclear[5], bem como a possibilidade de executar simulações em tomografias por emissão de pósitron (PET) e por emissão de fóton único (SPECT) evitando limitações presentes em códigos até então existentes.

GATE é o acrônimo de Geant4 Application for Emission Tomography e o Geant4 é uma ferramenta de simulação da interação da radiação com a matéria desenvolvida por um grupo de pesquisadores em física das radiações, tendo aplicações no estudo de física de alta energia, radiação espacial e aplicações médicas[6]. Um grupo de pesquisadores franceses validaram o GATE através de publicações, tornando este ambiente confiável para realização de simulações em tomografias por emissão de pósitrons obtendo resultados satisfatórios comparados com equipamentos já existentes no mercado[7].

Uma vez elaborado o equipamento virtual e realizadas as devidas simulações, torna-se necessário os testes de validação do sistema PET, com o propósito de garantir os resultados obtidos. Para isto, utilizou-se o protocolo publicado pela Assossiação Americana National Electrical Manufactures Association NEMA NU 2-2007[8]. Os testes foram realizados de acordo com especificações desta norma e, então, validados conforme resultados obtidos.

Com o uso de uma geometria diferenciada, em forma elíptica, espera-se o aumento da sensibilidade do sistema bem como a melhora na sua resolução espacial comparado ao sistema de geometria convencional. A sensibilidade depende do ângulo sólido coberto por cada detector[1], o qual deve ser ampliado para alguns detectores em virtude da nova geometria, principalmente nos cristais dispostos horizontalmente. 
Já a resolução espacial, depende da largura aparente dos cristais de detecção[1], conforme será discutido na seção 2.5.1 deste material. Na geometria convencional, os blocos de cristais apresentam pequenos ângulos entre eles. Esta angulação, está diretamente relacionada a largura aparente entre os blocos e, a redução do ângulo entre os blocos de cristais, possibilitaria a redução da largura aparente entre eles. Desta forma, espera-se que para o sistema PET elíptico, consiga-se a redução destes ângulos entre os detectores, principalmente para os blocos de cristais distribuídos na horizontal o que geraria melhoras na resolução espacial do sistema proposto.

O objetivo deste trabalho é avaliar o desempenho de um sistema PET, hipotético, constituído de sistema de blocos de cristais em arranjo elipsoidal. 


\section{Fundamentos Teóricos}

Um dos principais métodos de imagens tomográficas em Medicina Nuclear (MN) é a Tomografia por Emissão de Pósitrons (PET). Este método só pode ser utilizado fazendo-se uso de radionuclídeos emissores de pósitrons, como por exemplo, o Fluor-18. Os detectores PET detectam os fótons resultantes da aniquilação elétron-pósitron, conhecidos como fótons de aniquilação, que são emitidos em direções opostas, com energia de $511 \mathrm{keV}$.

Em decaimento radioativo, por emissão de pósitron, um próton, no núcleo é transformado em um nêutron e um elétron carregado positivamente (pósitron). Matematicamente, o processo é dado por:

$$
p^{+} \rightarrow n+\beta^{+}+v+\text { energia }
$$

onde o pósitron $\left(\beta^{+}\right)$é a anti-partícula do elétron sendo o pósitron e o neutrino ejetados do núcleo[9].

Um elétron e um pósitron, estando essencialmente em repouso próximos um do outro, se unem e são aniquilados. Uma vez que o momento inicial do sistema é zero, e como o momento deve se conservar no processo, não se pode criar apenas um fóton, pois um único fóton não pode ter momento zero. O processo que tem maior probabilidade de ocorrer é a criação de dois fótons que se movem com o mesmo momento em sentidos opostas. Menos provável, mas possível é a criação de três fótons.

No processo em que dois fótons são criados, a conservação do momento dá $0=\mathbf{p}_{\mathbf{1}}+$ $\mathbf{p}_{2}$, ou $\mathbf{p}_{1}=-\mathbf{p}_{2}$ de forma que os momentos dos fótons são iguais em módulos mas em sentidos opostos[10]. Ao passar através da matéria, um pósitron perde energia cinética em colisões sucessivas até se combinar com um elétron formando um sistema ligado chamado de positrônio, que possui o pósitron como núcleo. O positrônio tem uma vida curta, decaindo em fótons em aproximadamente $10^{-10} \mathrm{~s}$ após a sua formação[9]. Presume-se que o elétron e o pósitron se movam em torno do seu centro de massa, combinado-se em uma reação de aniquilação em que suas massas são convertidas em energia. É necessário uma energia de transição mínima de $1,022 \mathrm{MeV}$ para ocorrer o decaimento $\beta^{+}$.

O equivalente massa-energia de cada partícula é $511 \mathrm{keV}$. Essa energia aparece na forma de dois fótons de aniquilação que deixam o local onde ocorreu a aniquilação em 
direções quase exatas $\left(180^{\circ}\right)$, uma vez que podem variam em até $0,5^{\circ}$. $\mathrm{O}$ excesso de energia de transição, acima de 1,022 MeV é compartilhado entre o pósitron e o neutrino[9].

\subsection{Princípios Básicos de Imagens PET}

\subsubsection{Detecção de Coicidências de Aniquilação.}

Tomografia por Emissão de Pósitrons (PET) é baseado na detecção de dois fótons resultantes da aniquilação elétron-pósitron[11] Figura 1. Os fótons apresentam energia de $511 \mathrm{keV}$, e são emitidos simultaneamente, em direções opostas, formando, entre eles, um ângulo de $180^{\circ}$. A aniquilação ocorre próximo a região onde o pósitron foi emitido, geralmente entre alguns décimos de milímetros e alguns milímetros do local de emissão, dependendo da energia e do alcance dos pósitrons[1]. O alcance médio do pósitron emitido pelo ${ }^{18} \mathrm{~F}$ é mostrado na Tabela 1.

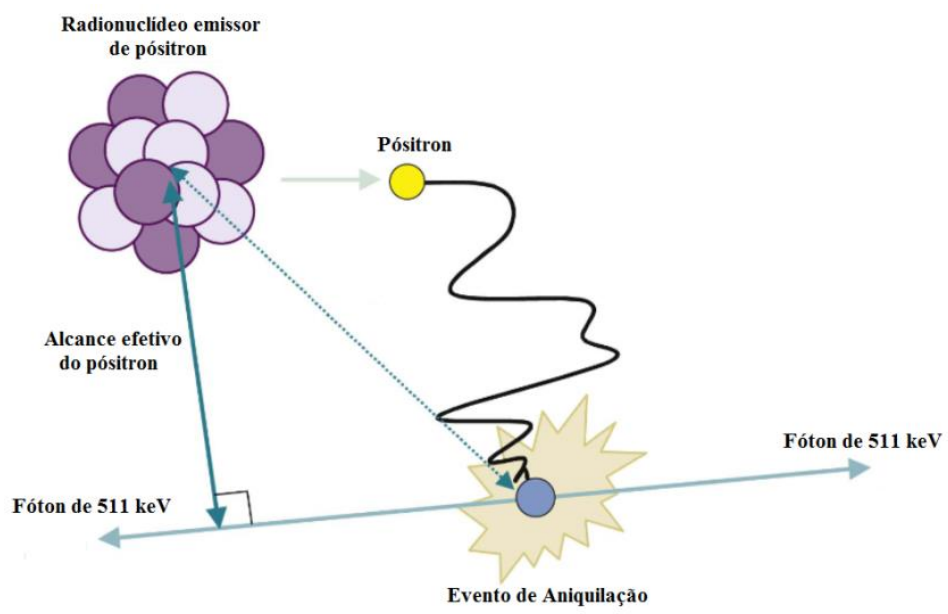

Figura 1: Aniquilação elétron-pósitron. Imagem adaptada de Physics in Nuclear Medicine, $4^{\mathrm{a}}$ Edição (Cherry, S. R., et al).

\begin{tabular}{|c|c|c|c|}
\hline Radionuclídeo & Ar $(\mathbf{c m})$ & Água $(\mathbf{c m})$ & Alumínio $(\mathbf{c m})$ \\
\hline${ }^{18} \mathrm{~F}$ & 176 & $0,23(0.06)$ & 0,084 \\
\hline
\end{tabular}

Tabela 1: Alcance máximo do pósitron oriundo do decaimento do ${ }^{18} \mathrm{~F}$, cuja energia máxima é de $635 \mathrm{keV}$. O Alcance médio na água é de $0,06 \mathrm{~cm}$, ou 0,6 mm. 
A detecção quase simultânea, dos fótons de aniquilação, permite ao PET localizar a origem ao longo da linha entre os detectores, sem o uso de colimadores. Este processo é conhecido como Detecção de Coincidências de Aniquilação (ACD - do inglês Annihilation Coincidence Detection). A detecção de um par de fótons de aniquilação, em detectores opostos, define o volume no qual eles foram emitidos. Este volume é, geralmente, uma caixa de seção tranversal quadrada ou retangular, uma vez que, os detectores ACD tem seções transversais nestes formatos. $\mathrm{O}$ volume no espaço no qual o pósitron emitido produz uma coincidência em um par de cristais é distribuído sobre um tubo de resposta (TOR- do inglês Tube of Response) ao longo de uma linha de resposta (LOR - do inglês Line of Response)[12]. Uma representação esquemática da TOR e da LOR pode ser vista na Figura 2.

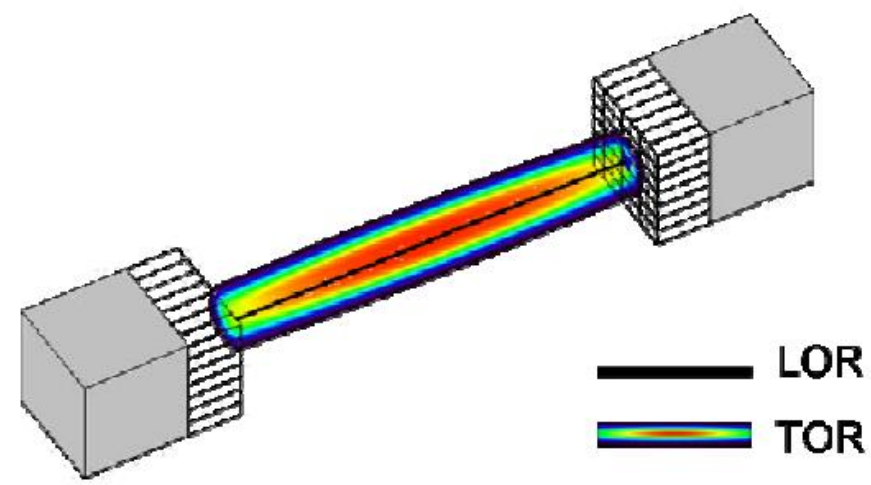

Figura 2: Respresentação da TOR e LOR entre 2 blocos de detectores. Adaptado de Optimal and Robust PET Data SinogramRestauration Based on the Response of the System (Herraiz, J.L.; et al).

Um evento de coincidência ocorre quando um par de fótons de aniquilação é registrado dentro de um intervalo de tempo específico, conhecido por janela de coincidência, que é da ordem de 6 a 12 ns. Embora ocorra a emissão dos fótons de aniquilação simultaneamente, uma pequena, mas finita janela de coincidência é necessária para permitir as diferenças de tempo no trajeto dos sinais, bem como diferentes distâncias de viagens entre dois fótons de aniquilação até alcançarem os detectores[1]. A necessidade da janela de coincidência permite ocorrer alguns outros tipos de coincidências, a serem discutidas na seção 2.1.3.

A capacidade do ACD em localizar eventos baseados em um intervalo de tempo, sem a necessidade de um colimador absorvedor é conhecido como colimador eletrônico. Como o ACD não necessita de colimadores para definir a localização espacial dos eventos, sua sensibilidade (número de eventos detectados por unidade de atividade no objeto) é maior que 
os obtidos com o uso do colimador absorvedor das imagens planas e de SPECT, o que faz com que a sensibilidade no PET seja muitas vezes maior que no SPECT[1].

Os atuais sistemas PET, possuem detectores arranjados em forma circular, envolvendo completamente o corpo do paciente, sendo possível adquirir dados para todos os ângulos de projeções, em torno do paciente, simultaneamente.

\subsubsection{Tempo de Voo}

A capacidade em medir o tempo de voo (TOF - do inglês Time-of-flight) promete melhorar a qualidade das imagens em sistemas PET, uma vez que, medida do TOF de dois fótons de aniquilação permite localizar com maior precisão o ponto onde ocorreu o evento de aniquilação, que depende da resolução temporal do sistema[13]. Em outras palavras, é possível determinar a localização ao longo da linha entre 2 detectores ACD que originou os fótons de aniquilação determinando a variação no tempo em que estes fótons foram detectados[1].

Se a diferença nos tempos de chagada dos fótons é $\Delta \mathrm{t}$, a localização dos eventos de aniquilação, com respeito ao ponto médio entre 2 detectores é dado por:

$$
\Delta d=\frac{\Delta t \times c}{2}
$$

onde c é a velocidade da luz $\left(3 \times 10^{10} \mathrm{~cm} / \mathrm{s}\right)$.

\subsubsection{Tipos de eventos em Detectores de Coincidências de Aniquilação[14]}

Os sistemas PET utilizam-se dos fótons de aniquilação provenientes da aniquilação elétron-pósitron que são detectados nos cristais do tomógrafo. Diz-se ter ocorrido os eventos de coincidências satisfazendo-se as três condições abaixo descritas:

- Dois fótons são detectados dentro da janela temporal pré-definida conhecida como janela de coincidência;

- A LOR formada entre os detectores deve estar dentro do ângulo de aceitação válido no tomógrafo; 
- A energia depositada no cristal, por ambos os fótons de aniquilação, deve estar dentro de uma janela de energia selecionada.

O FOV transaxial de um sistema PET é definido pelo ângulo de aceitação no plano. Isto é determinado pela eletrônica, que permite que um detector individual esteja em coincidência com um número finito de detectores no lado oposto do anel [14]. O ângulo de aceitação está representado na Figura 3.

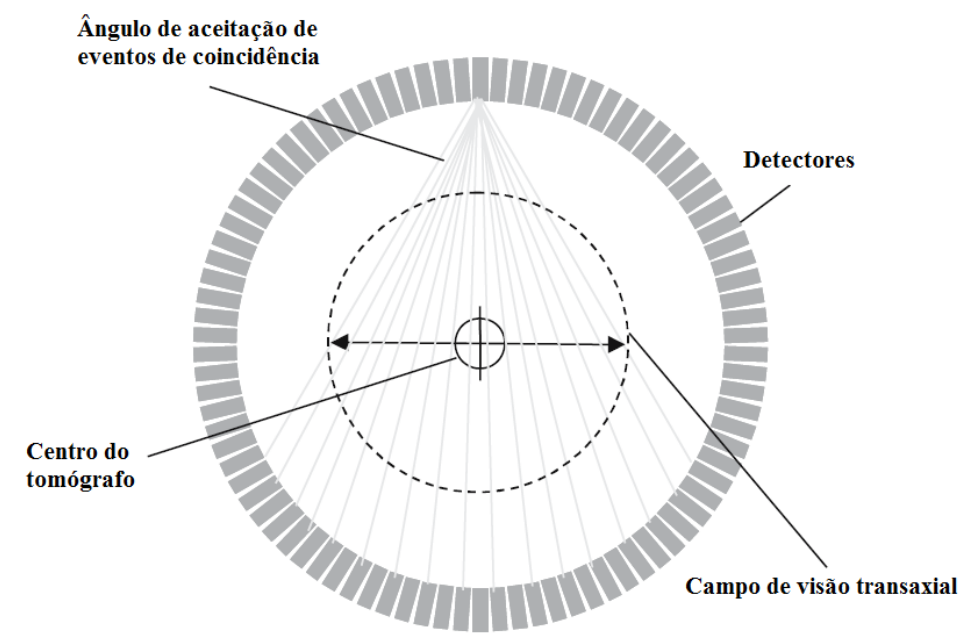

Figura 3: Campo de visão transaxial do PET definido pelo ângulo de aceitação do sistema. Adaptado do livro Positron Emission Tomography (Dale L. Bailey, et al).

Uma vez que estas condições sejam satisfeitas, os eventos em sistemas PET podem ser classificados como: coincidências verdadeiras, espalhadas, aleatórias e múltiplas, como mostra a Figura 4 . 


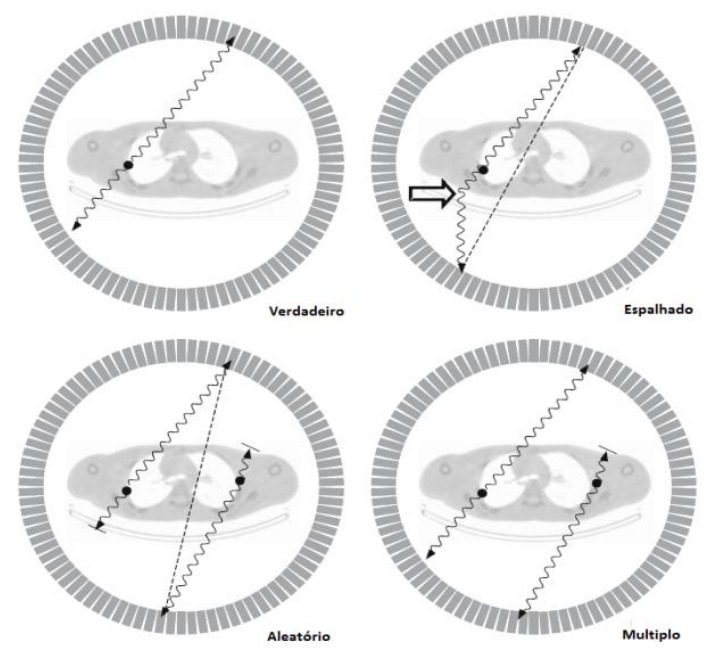

Figura 4: Eventos de coincidências em Sistemas PET. Adaptado do livro Positron Emission Tomography (Dale L. Bailey, et al).

As coincidências verdadeiras ocorrem de uma única aniquilação elétron-pósitron. Os dois fótons de aniquilação alcançam ambos os detectores em lados opostos do tomógrafo dentro do intervalo da janela de coincidência.

As coincidências espalhadas surgem quando um, ou ambos os fótons, de uma única aniquilação de pósitron detectado dentro da janela de coincidência sofre espalhamento Compton perdendo parte de sua energia e, desta forma, alterando sua direção. Como principal consequência das coincidências espalhadas, destaca-se o fato de que a LOR atribuída ao evento não condiz com o local exato da aniquilação elétron-pósitron, o que gera inconsistência nos dados de projeção conduzindo a uma diminuição do contraste e quantificação imprecisa na imagem final.

As coincidências aleatórias ocorrem quando dois núcleos decaem aproximadamente ao mesmo tempo. Após ocorrer a aniquilação de ambos os pósitrons, quatro fótons de aniquilação são emitidos, porém, são registrados, dentro da janela de coincidência, dois fótons de diferentes aniquilações, mas considera-se vindos do mesmo pósitron, enquanto os outros dois são perdidos ou geram uma segunda coincidência aleatória.

As coincidências múltiplas são semelhantes as aleatórias, mas diferem no fato de que, são detectados, dentro da janela de coincidência, três fótons proveniente de duas ou mais aniquilações distintas. 
Quando há mais que dois singles em coincidência, diversos tipos de comportamentos podem ser implementados. A interação de um fóton de aniquilação com o detector, gera um pulso, que será aqui chamado de singles.

A fim de cobrir uma grande variedade de aplicações, o GATE permite escolher diferentes regras para se aplicar nestes casos. A Tabela 2 mostra uma lista destas regras juntamente com suas descrições.

\begin{tabular}{|c|l|}
\hline Nome & \multicolumn{1}{c|}{ Descrição } \\
\hline takeAllGoods & Todos os bons pares são considerados. \\
\hline takeWinnerOfGoods & Considera-se apenas os bons pares com maiores energia. \\
\hline takeWinnerIfIsGood & $\begin{array}{l}\text { Se o par de maior energia é considerado bom, mata-se os eventos que não } \\
\text { satisfizerem essa condição. }\end{array}$ \\
\hline takeWinnerIfAllAreGoods & Se todos os pares são bons, pegar aquele de maior energia . \\
\hline keepIfOnlyOneGood & Se exatamente um par é bom, manter todas as multicoincidências. \\
\hline keepIfAnyIsGood & Se pelo menos um par é bom, manter todas as multicoincidências. \\
\hline keeplfAllAreGood & $\begin{array}{l}\text { Se todos os sub-pares são considerados, mantenha todas as coincidências } \\
\text { múltiplas. }\end{array}$ \\
\hline killAllIfMultipleGoods & $\begin{array}{l}\text { Se mais que um par é bom, o evento é visto como reais múltiplos e assim, } \\
\text { todos os eventos são mortos. }\end{array}$ \\
\hline killAll & $\begin{array}{l}\text { Não aceita-se várias coincidências, não importa quantos pares bons estão } \\
\text { presentes. }\end{array}$ \\
\hline
\end{tabular}

Tabela 2: Descrição dos vários tipos de coincidências múltiplas que podem ser implementadas no GATE. Quando uma coincidência múltipla, envolvendo n singles é processada, primeiramente é decomposta em uma lista de n(n-1) pares que são analisados individualmente. Nesta tabela o termo good (bom) significa que um par de singles estão em coincidência e que os dois singles são separados por um determinado número de blocos. $\mathrm{O}$ prefixo take significa que um ou mais pares de coincidências serão armazenados, enquento que o prefixo keep significa que uma única coincidência composta por pelo menos três singles será mantido no fluxo de dados e é conhecido por coincidências múltiplas. O prefixo kill significa que todos os eventos serão descartados e não produzirá nenhuma coincidência. Tabela adaptada de OpenGATEcollaboration: [www.opengatecollaboration.org].

A comparação dos efeitos de cada regra, para cada caso de coincidências múltiplas é mostrado na Figura 5. 


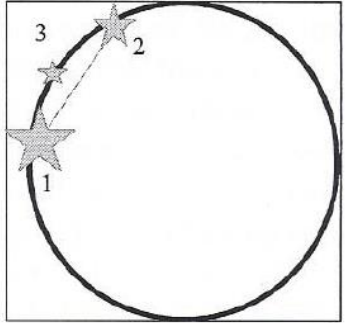

Caso 1

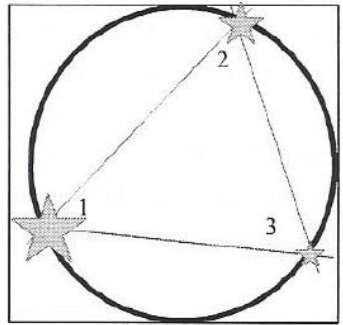

Caso 2

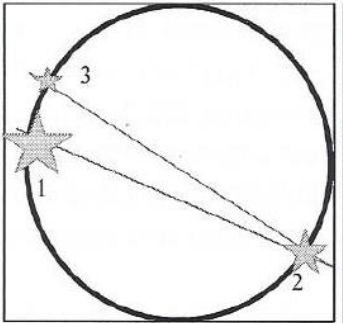

Caso 3

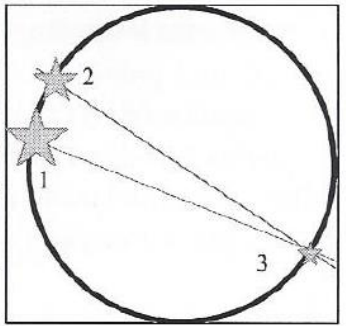

Caso 4

Figura 5: Comparação do comportamento de vários tipos de processamentos disponíveis para várias situações de múltiplas coincidências. As estrelas representam os singles detectados. O tamanho da estrela, bem como o número ao lado, indica o nível de energia do single (por exemplo: o single $\mathrm{n}^{\mathrm{o}} 1$ tem maior energia que o single $\mathrm{n}^{\circ}$ 2, que por sua vez, tem maior energia que o single $\mathrm{n}^{\mathbf{0}} 3$ ). As linhas representam as possíveis coincidências. Figura adaptada de OpenGATEcollaboration: [www.opengatecollaboration.org].

A Tabela 3, exemplifica como podem ser consideradas as coincidências múltiplas de acordo com cada caso mostrado na Figura 5.

\begin{tabular}{|c|c|c|c|c|}
\hline Nome & Caso 1 & Caso 2 & Caso 3 & Caso 4 \\
\hline takeAllGoods & $(1,2)$ & $(1,2) ;(1,3) ;(2,3)$ & $(1,2) ;(2,3)$ & $(1,3) ;(2,3)$ \\
\hline takeWinnerOfGoods & $(1,2)$ & $(1,2)$ & $(1,2)$ & $(1,3)$ \\
\hline takeWinnerIfIsGood & $(1,2)$ & $(1,2)$ & $(1,2)$ & - \\
\hline takeWinnerIfAllAreGoods & - & $(1,2)$ & - & - \\
\hline keepIfOnlyOneGood & $*$ & - & - & - \\
\hline keepIfAnyIsGood & $*$ & $*$ & $*$ & - \\
\hline keepIfAllAreGood & - & $*$ & - & - \\
\hline killAllIfMultipleGoods & $(1,2)$ & - & - & - \\
\hline killAll & - & - & - & $*$ \\
\hline
\end{tabular}

Tabela 3: Tabela associada a figura 5. O sinal (-) significa que o evento é morto (nenhuma coincidência é formada. O sinal $(*)$ indica que todos os singles são armazenados em uma única coincidência múltipla que não serão gravados nos discos, mas que podem influenciar na perda de dados através do tempo morto. Nestes outros casos, a lista dos pares que podem ser registrados (a não ser que sejam removidos posteriormente por um possível filtro aplicado as coincidências) é indicado. Tabela adaptada de OpenGATEcollaboration: [www.opengatecollaboration.org].

\subsection{Detectores PET}

Uma vez que a eficiência de detecção é um importante parâmetro para sensibilidade e desempenho dos sistemas PET, os detectores utilizados por estes equipamentos são importantes para melhores resultados. Os detectores de Iodeto de Sódio (NaI), comumente utilizados em equipamentos de Medicina Nuclear, tem seu desempenho comprometido, para sistemas PET, devido a energia relativamente alta $(511 \mathrm{keV})$ dos fótons de aniquilação. 
Com a necessidade de melhorar a eficiência de detecção dos sistemas PET, novos detectores foram desenvolvidos com objetivo de detectar os fótons de maior energia proveniente das aniquilações. Desta forma, desenvolveram-se os detectores de LSO (Oxiortosilicato de lutécio) e BGO (Oxi-Germanato de Bismuto), que melhoraram a capacidade do tomógrafo em detectar os fótons de $511 \mathrm{keV}$ [11]. Por esta razão, sistemas PET, utilizam detectores cintiladores, arranjados em forma de anel ou conjunto de elementos discretos em torno do objetos a ser imageado.

Estes sistemas, não só apresentam alta eficiência de detecção, mas também permitem a aquisição de dados simultâneos, para todos os ângulos de projeções de um conjunto de detectores estacionários.

\subsection{Aquisição de dados em Sistemas PET}

Aquisição de dados em sistemas PET, utilizados com maior frequência são: bidimensionais (2D) e tridimensionais (3D).

\subsubsection{Aquisição de dados $2 \mathrm{D}$}

O processo de aquisição dos dados 2D, em sistemas PET, faz uso de colimadores, ou septos entre os anéis de detecção. Como mostra a Figura 6A, os septos permitem apenas que os fótons emitidos paralelamente ao plano do detector sejam detectados, e consequentemente, faz com que a sensibilidade do sistema seja baixa. Os septos também ocasionam diminuição dos fótons espalhados no objeto[1].

Utilizando-se um sistema com múltiplos anéis de detecção, obtêm-se uma série de configurações 2D, no plano transaxial da imagem. Com pouca, ou nenhuma modificação no comprimento dos septos, o PET pode também adquirir dados de anéis adjacentes, como pode ser visto na Figura 6B. Este processo, que pode ser denominado de planos cruzados, acarreta um aumento na sensibilidade do sistema. 
No sistema PET, os planos cruzados interceptam-se exatamente no meio dos planos paralelos e, para efeito de análise, considera-se que os dados dos planos cruzados são adquiridos de anéis "virtuais", localizados nos espaços entre os detectores.

Sistemas PET, formados de pequenos blocos de detecção, o número de planos cruzados pode aumentar, levando em consideração não apenas os cristais imediatamente ao lado, mas com intervalos de $\pm 2, \pm 3$ e assim por diante, como pode ser visto na Figura 6C. Como a diferença entre os cristais aumenta, a sensibilidade desse sistema também aumenta, contudo ocorre uma degradação na resolução espacial devido a superposição dos dados.

\subsubsection{Aquisição de dados 3D}

Para aquisição de dados 3D, em sistemas PET, remove-se os septos e os dados são obtidos para todas as linhas de respostas possíveis, como mostrado na Figura 6D. A remoção dos septos faz com que a sensibilidade do sistema seja de 4 a 8 vezes maiores do que com a presença dos septos. Consequentemente, ocorre o aumento dos fótons espalhados que são detectados. Por exemplo, em um exame de cérebro, usando o modo de aquisição 3D, cerca de 30 a $40 \%$ dos fótons detectados, foram espalhados antes de atingirem os detectores.O perfil de sensibilidade axial, de aquisição 3D, é determinado geometricamente, e é uma função triangular com picos no centro do FOV. Em modo 3D, é importante colocar a estrutura de interesse o mais próximo possível do centro do FOV axial. 


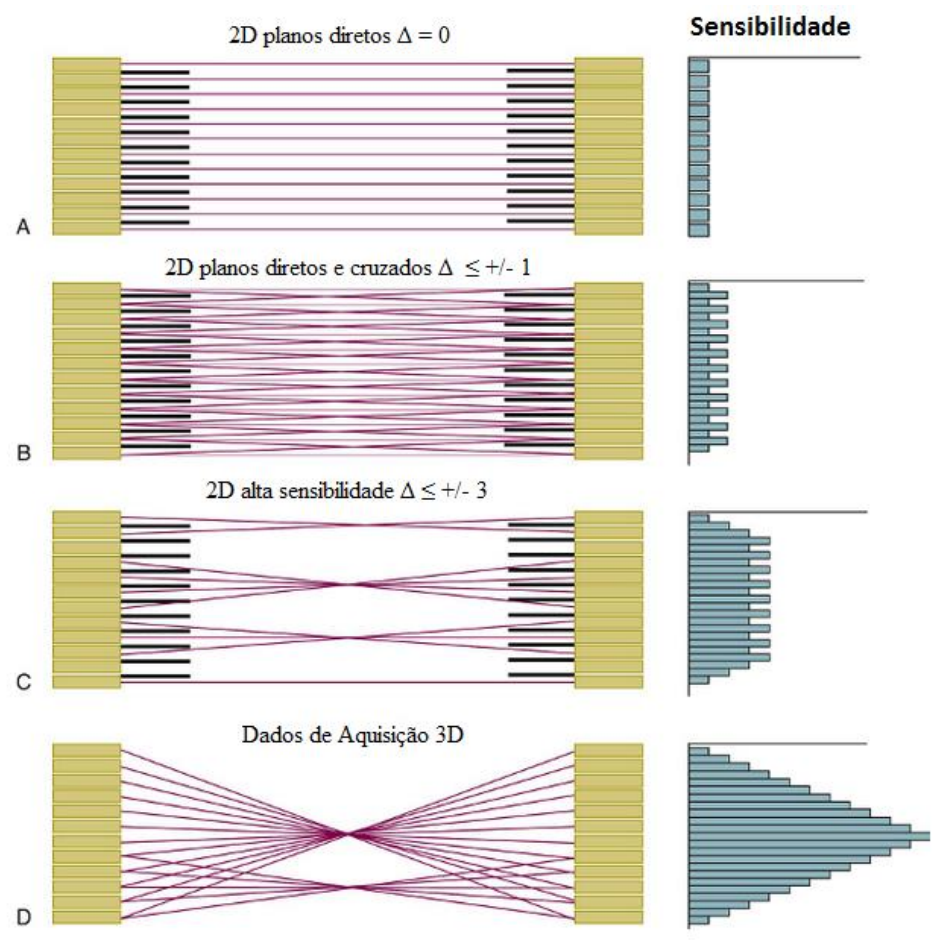

Figura 6: Esquema de aquisição de dados 2D e 3D para sistemas PET. Imagem adaptada de Physics in Nuclear Medicine, $4^{\mathrm{a}}$ Edição (Cherry, S. R., et al).

\subsection{Obtenção dos eventos de Coincidências [6]}

Sempre que dois ou mais singles são encontrados dentro de uma janela de coincidência temporal, estes singles são agrupados para formar um evento de coincidência. Dois métodos são possíveis para encontrar coincidências no GATE.

No primeiro método, quando um single é detectado ele abre uma janela de coincidência temporal e busca por um segundo single que seja detectado dentro deste intervalo de tempo. Neste método, enquanto a janela de coincidência aberta pela detecção do primeiro single não for fechada pela detecção de outro single, não haverá abertura de novas janelas para outras detecções.

O segundo método, tem-se todos os singles abrindo a sua própria janela de coincidência e faz uso de todos os sinais individuais para encontrar as coincidências. Desta forma, o primeiro single varre todos os demais sinais possíveis dentro da janela de coincidência temporal, para então gerar todas as coincidências possíveis neste intervalo de tempo específico. 


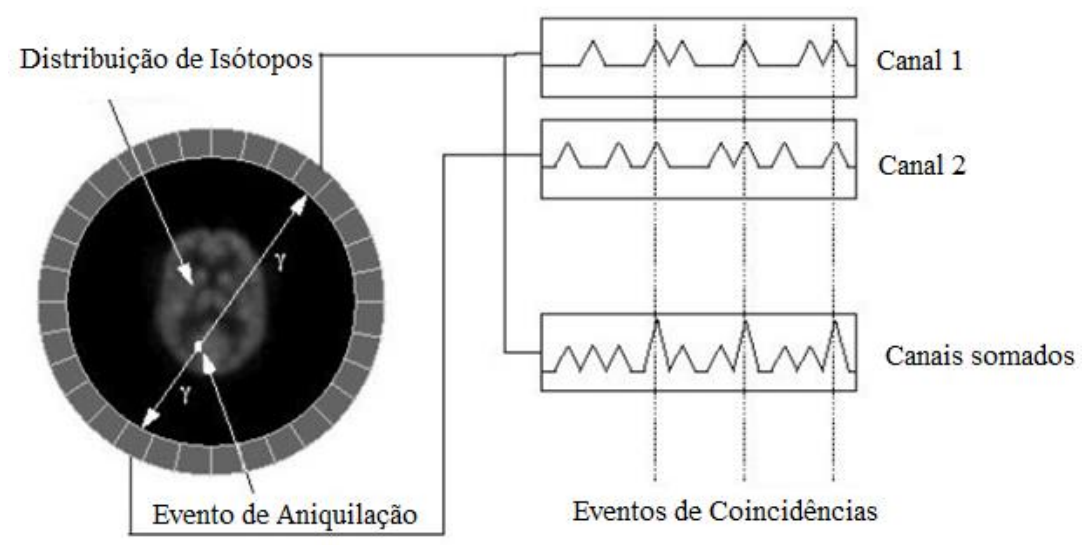

Figura 7: Obtenção dos eventos de coincidências através de pulsos (singles) individuais[15]. Imagem adaptada de Emission Tomography: The Fundamentals of PET and SPECT, 180 p. (Miles N. Wernick and John N. Aarsvold).

Um método para estimativas de aleatórios se dá quando cada single emitido de uma dada partícula fonte é armazenado por um número de event $I D$, que identifica o decaimento a partir do qual o single foi emitido. Se dois números de event ID são diferentes para um dado evento de coincidência, este é definido como coincidência aleatória.

Outro método utilizado para estimar o número de coincidências aleatórias consiste do uso de uma janela de coincidência temporal atrasada (delayed). Por definição, a janela de coincidência é aberta quando uma partícula é detectada. Neste método, utilizando-se o delayed, uma segunda janela de coincidência é gerada em paralelo, em comparação com a janela de coincidência normal. Esta segunda janela aberta é deslocada no tempo e este deslocamento deve ser longo o suficiente para garantir que as duas partículas detectadas estão chegando de diferentes decaimentos.

\subsection{Sinogramas}

Os atuais sistemas PET, em sua maioria, apresentam detectores de cristais arranjados em forma circular. Durante o exame, o tomógrafo adquire um conjunto muito grande de projeções, com intervalos angulares igualmente espaçados ao redor do paciente, que devem ser armazenados para processamentos posteriores. 
Para análise, é conveniente alterar o sistema de coordenadas, que é estacionário com relação ao tomógrafo e está representado na Figura 8 passando de coordenadas cartesianas para polares, como mostrado nas equações abaixo.

$$
\begin{aligned}
& r=x \cos \phi+y \sin \phi \\
& s=y \cos \phi-x \sin \phi
\end{aligned}
$$

As equações (3) e (4) ajudam a determinar a localização da radioatividade (x,y) no objeto contribui para o registro do sinal na localização, r, das projeções adquiridas num ângulo de rotação $\phi$.

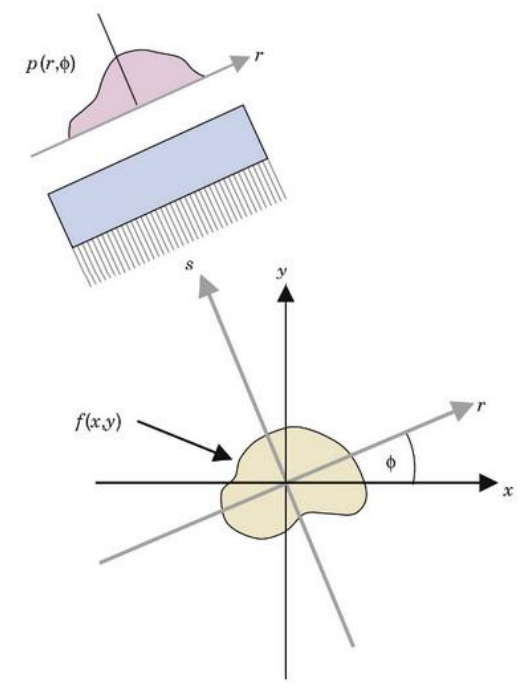

Figura 8: Novo sistema de coordenadas $(r, s)$ rotacionado pelo ângulo de rotação $\phi$ em relação ao sistema de coordenadas (x,y). Adaptado de Physics in Nuclear Medicine, $4^{\mathrm{a}}$ Edição (Cherry, S. R., et al).

Uma forma muito comum de armazenar estes dados de projeções é através de uma matriz $2 \mathrm{D}, \mathrm{p}(\mathrm{s}, \phi)$ também conhecida como sinograma. Uma representação desta matriz pode ser vista na Figura 9. 


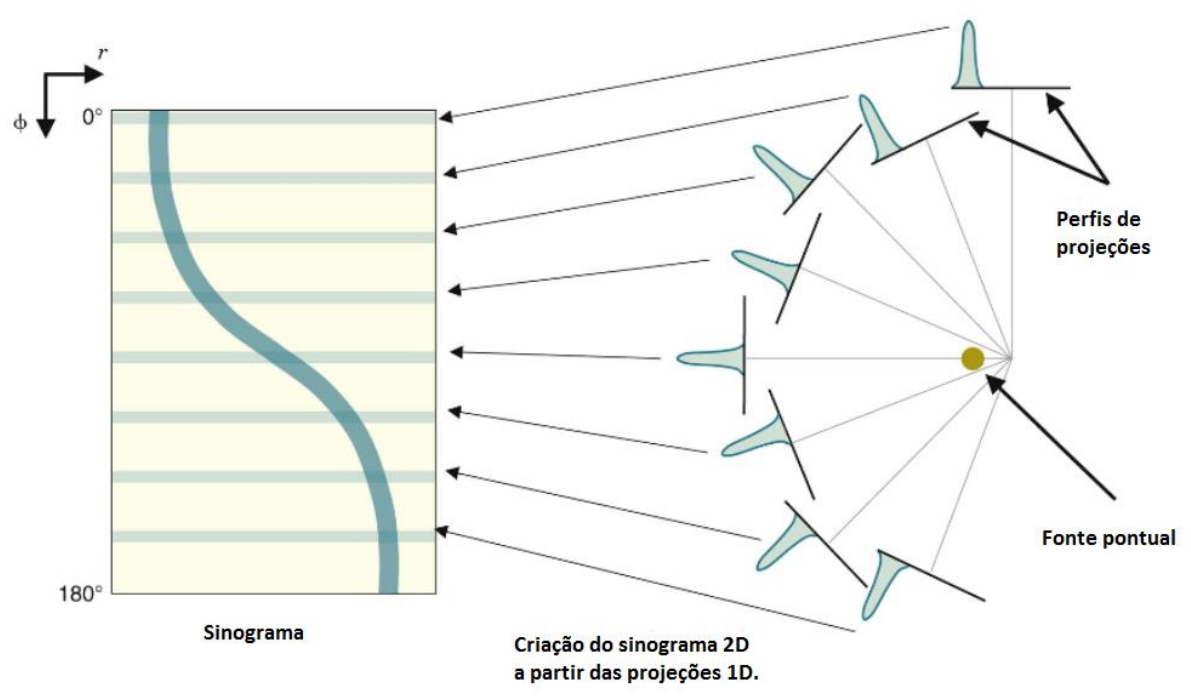

Figura 9: Criação do sinograma 2D através de um conjunto de projeções $1 \mathrm{D}$ gerado à partir de uma fonte pontual. Cada linha corresponde a uma projeção individual e as sucessivas linhas representam sucessivos ângulos de projeções. Adaptado de Physics in Nuclear Medicine, $4^{a}$ Edição (Cherry, S. R., et al).

Todos os dados adquiridos em um sistema PET são organizados em sinogramas, de forma semelhante as gamacâmaras planas[1]. Cada par de detectores e a respectiva LOR correspondem a um pixel no sinograma que está associada a orientação angular e a distância do centro à LOR. Desta forma, para cada coincidência detectada localiza-se a LOR correspondente a este evento e, de igual modo, o seu pixel no sinograma[11].

O sinograma representa uma forma conveniente para representar um conjunto total de dados adquiridos durante uma aquisição e, pode ser útil, para determinar as causas de artefatos em imagens PET e SPECT[1].

Para geometria circular, o sistema de coordenadas que deve ser usado para descrever sistemas PET é mostrado na Figura 10: 


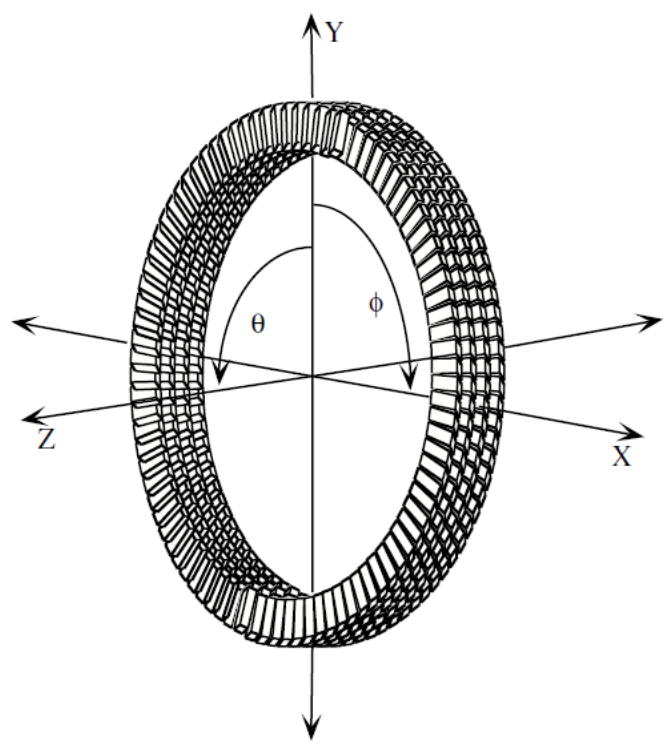

Figura 10: Representação da geometria e da coordenada de um sistema PET convencional. O ângulo azimutal $(\phi)$ é medido em torno do anel, enquanto o ângulo polar $(\theta)$ é medido entre os anéis. Imagem adaptada do livro Positron Emission Tomography (Dale L. Bailey, et al).

Os sinogramas formados em PET, são compostos de projeções p(s, $\phi, \theta, \mathrm{z})$. Em casos 2$\mathrm{D}$, assume-se o ângulo polar $\theta=0^{\circ}$. Já para os casos 3-D, obtêm-se projeções com ângulos polares $\theta>0^{\circ}$. Uma representação gráfica, conhecida como Michelograma, foi introduzida pelo cientista belga Christian Michel para ilustrar os planos de definições usados para sistemas PET com múltiplos anéis, mostrando como esses planos podem ser combinados para otimizar o espaço de armazenamento e a manipulação dos dados[14]. A Figura 11 mostra diferentes modo de aquisição em um Michelograma para um simples tomógrafos de 8 anéis. 

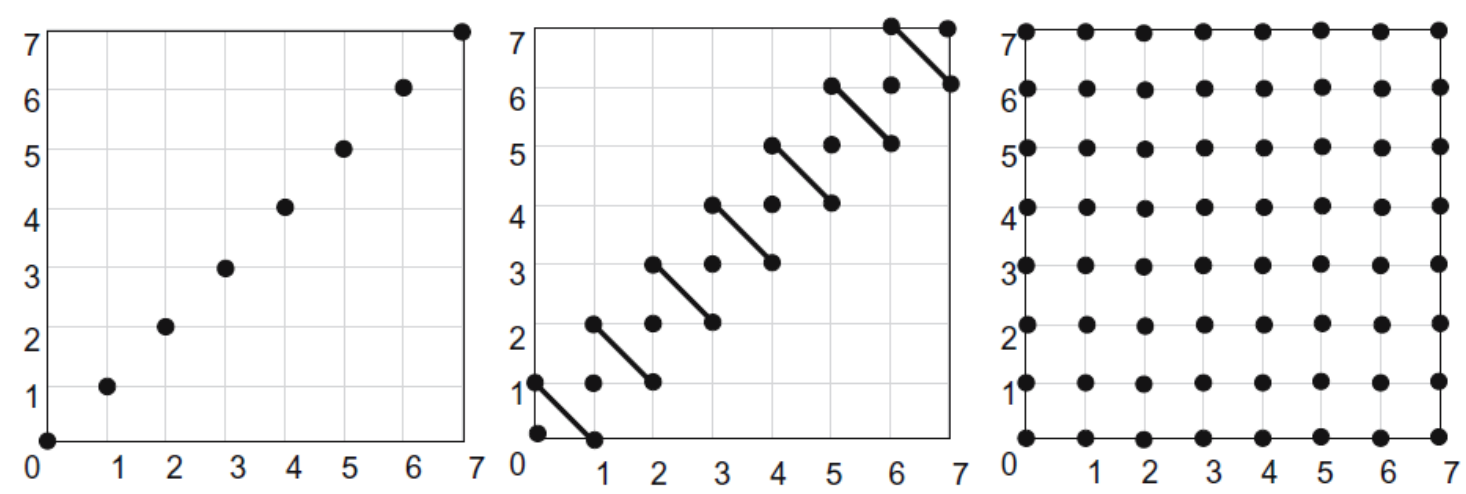

Figura 11: Representação do Michelograma para três diferentes modos de aquisições em um tomógrafo com oito anéis. Cada ponto no gráfico representa um plano de resposta definido entre dois conjuntos de detectores opostos (sinogramas). O gráfico a esquerda, o primeiro plano definido é o anel 0 em coincidência com o detector oposto no mesmo anel 0 , o anel 1 em coincidência com o anel 1 e assim por diante, para todos os anéis, totalizando 8 sinogramas. No gráfico do meio, os mesmos planos são adquiridos com a adição de um conjunto nos espaços entre os detectores, com diferença de \pm 1 anel (anel 0 com anel 1 , anel $1 \mathrm{com}$ anel 0 , etc). $\mathrm{O}$ gráfico à direita mostra sistema de aquisição 3D em que cada conjunto de dados é armazenado separadamente (no total de 64 sinogramas).Imagem adaptada do livro Positron Emission Tomography (Dale L. Bailey, et al).

A Figura 12 define as variáveis s e $\phi$, usadas para parametrizar uma linha reta (LOR) entre os detectores $d_{a}$ e $d_{b}$ com respeito ao sistema de coordenadas cartesianas $(x, y)$.

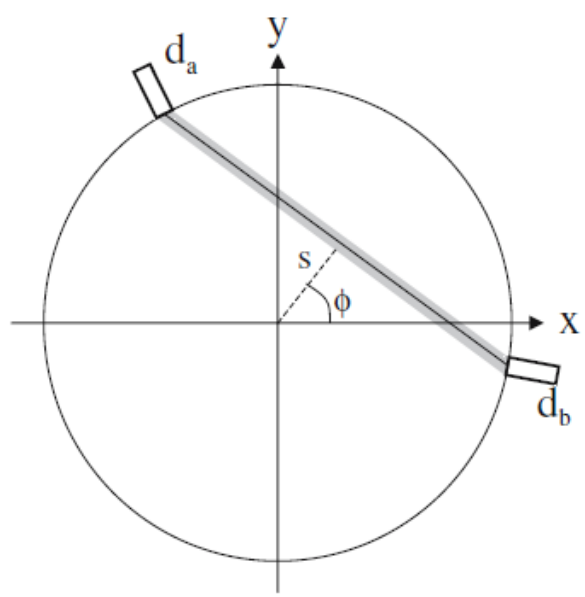

Figura 12: Representação de uma LOR entre os detectores da e db. As variáveis (s e $\phi$ ) do sinograma também estão representados na figura.Imagem adaptada do livro Positron Emission Tomography (Dale L. Bailey, et al).

As variáveis s e $\phi$ são variáveis do sinograma, onde s é a distância entre a LOR e o centro do sistema de coordenadas (geralmente o centro do anel de detecção) e a variável 
angular $\phi$, especifica a orientação da LOR. A integral de linha da distribuição do traçador, são então definidas como:

$$
p\left(s, \phi, z_{0}\right)=\int_{-\infty}^{\infty} d t f\left(x=s \cos \phi-t \sin \phi, y=s \sin \phi+t \cos \phi, z=z_{0}\right)
$$

onde t, a variável de integração, é a coordenada ao longo da linha. Na apresentação do problema de reconstrução 2D, omite-se o argumento z nas funções $p$ e $f$ [14].

Em PET 2D, os dados de emissão são projeções unidimensionais e ocorrem em torno do ângulo azimutal $\phi$, não variando o ângulo polar $\theta$. Em PET 3D, as projeções são bidimensionais, com ângulo azimutal $\phi$ e ângulo polar $\theta$ variando. $\mathrm{O}$ conjunto completo de dados de projeções é então representado por um conjunto completo de sinogramas e, para os casos em que o ângulo polar $\theta$ for diferente de zero, estes são rebatidos a um plano vertical, no centro da LOR. Desta forma, adquiri-se um sinograma para cada fatia, que será reconstruído posteriomente[11].

\subsection{Desempenho de sistemas PET}

\subsubsection{Resolução Espacial}

A resolução espacial de um sistema representa sua habilidade em distinguir entre dois pontos após a reconstrução da imagem[8]. A resolução espacial de um sistema PET, expresso como a largura total a meia altura (FWHM), resulta de uma combinação de fatores físicos e de instrumentação[11].O perfil da curva de resolução espacial é frequentemente descrito por uma função gaussiana[14]. O desvio padrão está relacionado com FWHM através da equação abaixo:

$$
F W H M=\sqrt{8 \log _{e} 2 \sigma}
$$

onde $\sigma$ é o desvio padrão da função gaussiana.

Há vários fatores que podem influenciar a resolução espacial em sistemas PET. Fisicamente, a resolução espacial pode ser degradada devido ao curto alcance do pósitron. $\mathrm{O}$ ACD define a linha ao longo na qual ocorreu o evento de aniquilação, que pode não representar com precisão, o local em que ocorreu o decaimento radioativo do núcleo emissor 
de pósitron. Outro fator, é que os fótons de aniquilação, quase nunca são emitidos exatamente a $180^{\circ}$ um do outro, podendo haver uma pequena variação angular $\left(0,5^{\circ}\right)$ entre eles.

A resolução espacial com elementos discretos de detecção é determinada, primeiramente pelo tamanho do detector. Como mostra a Figura 13, para elementos de largura (d), um corte 1D através do perfil de resposta de uma fonte pontual no ponto médio entre os pares de detectores é um triângulo, neste caso, a resolução do detector se dá por $F W H M=$ $d / 2$. Com a fonte se movendo em direção ao detector, o perfil de resposta torna-se trapezoidal, eventualmente tornando-se uma caixa de largura (d) na face de qualquer detector.

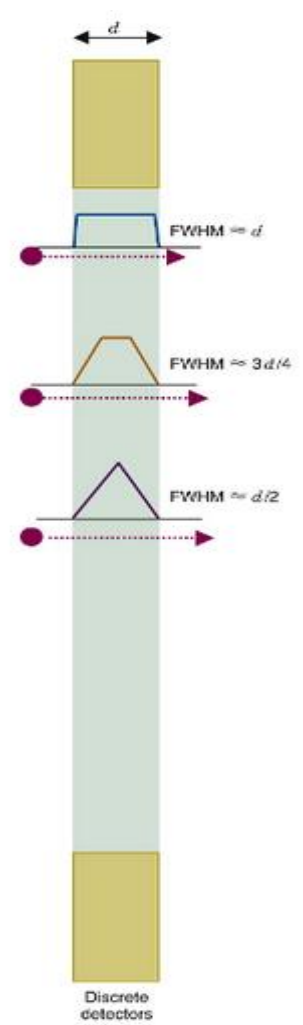

Figura 13: Resolução espacial para um par de detectores em coincidência. A resolução espacial $\left(R_{\text {det }}\right)$ é determinada pela largura (d) do detector. No plano médio, a FWHM é igual a d/2. Rdet varia conforme a fonte de aproxima do detector. Adaptado de Physics in Nuclear Medicine, $4^{a}$ Edição (Cherry, S. R., et al).

Um fator de instrumentação que pode degradar a resolução espacial é a profundidade de interação (DOI, do inglês Depth-of-Interaction) do fóton com o detector[14]. A Figura 14 mostra como a DOI pode afetar na resolução espacial de um sistema de detecção circular presente em PET. Através desta figura, percebe-se que a medida que os detectores se afastam 
do centro do scanner, aumenta-se a inclinação dos blocos e, consequentemente, a largura aparente (d') entre dois blocos.

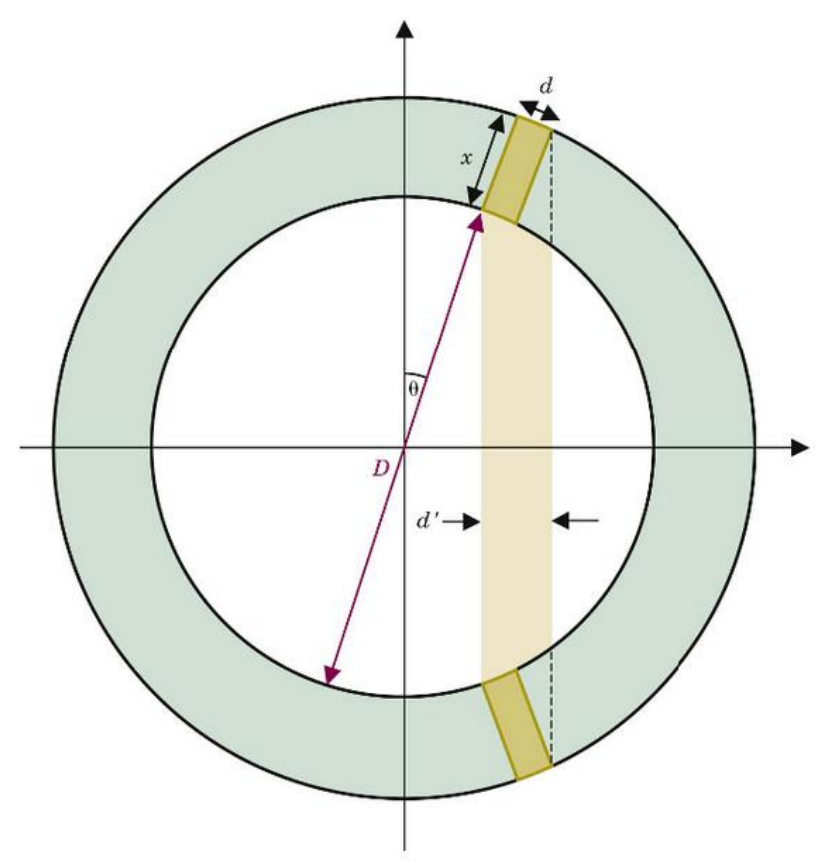

Figura 14: Largura aparente (d') do detector onde d' aumenta com o aumento do deslocamento radial em sistemas PET convencional arranjados em forma circular. Imagem adaptada de Physics in Nuclear Medicine, $4^{\mathrm{a}}$ Edição (Cherry, S. R., et al).

Para uma fonte localizada próxima ao centro do scanner, a resolução espacial é determinada pela largura do detector, $R_{\text {det }}=d / 2$. Porém, para uma fonte localizada longe do centro, a largura aparente do detector torna-se:

$$
d^{\prime}=d \cos \theta+x \sin \theta
$$

onde d, x e $\theta$ são indicados na Figura 14.

A aparente mudança na largura do detector resulta da angulação entre os detectores e da falta de informação referente a profundidade em que ocorreu a interação dentro detectores de cristais. A resolução espacial (FWHM) torna-se então $R_{\text {det }}^{\prime}=d^{\prime} / 2$. Usando a equação (7), isto pode ser escrito como:

$R_{\text {det }}^{\prime} \approx(d / 2) \times[\cos \theta+(x / d) \operatorname{sen} \theta] \approx R_{\text {det }} \times[\cos \theta+(x / d) \operatorname{sen} \theta]$ 
Através desta equação, verifica-se que o efeito da DOI é descrito por um fator multiplicativo $\left[\cos \theta+(x / d) \operatorname{sen} \theta\right.$ ] aplicado ao valor da resolução no detector $R_{\text {det }}$, no ponto médio entre pares de detectores opostos. Devido aos efeitos da DOI, PET scanner são frequentemente construídos com arranjos de deteç̧ão com maior diâmetro do que seria necessário para se ajustar o paciente, que por sua vez aumenta o custo dos detectores[1].

Outros fatores que podem influenciar na resolução espacial, em sistemas PET, são: os tipos ou tamanhos dos detectores, número de amostragem[1], distância entre os detectores, stopping power ${ }^{1}$ dos detectores cintiladores, os ângulos de incidência dos fótons nos detectores, parâmetros de reconstrução (tamanho da matriz, filtros de reconstrução)[14] entre outros.

\subsubsection{Taxa de Contagem de Ruído Equivalente (NEC)}

Um parâmetro de desempenho, muito utilizado nos sistemas PET, presente na norma é a Taxa de Contagem de Ruído Equivalente (NEC- do inglês, noise equivalent counting rate). Este parâmetro, específico de sistemas PET, diz respeito aos ruídos estatísticos adicionais introduzidos pela correção das coincidências aleatórias e espalhadas. O NEC é definido como a taxa de contagem equivalente que dá origem ao mesmo nível de ruído estatístico que a taxa de contagem observada depois que as coincidências aleatórias e espalhadas foram corrigidas[1].

A curva da taxa de contagem de ruído equivalente (NEC), que incorpora os efeitos de ruídos, subtraídos dos componentes de contagens aleatórios e espalhados, fornecem uma relação direta entre a razão sinal-ruído (SNR) e as taxas de contagens de coincidências verdadeiras, aleatórias e espalhadas[15].

O NEC é definido como[8]:

$$
N E C=\frac{T^{2}}{T+\alpha S+b R}
$$

\footnotetext{
${ }^{1}$ Stopping-power: é caracterizado pela distância média $(1 / \mu)$ percorrida pelo fóton antes que ele deposite a sua energia dentro do cristal[14]. Embora este termo seja definido para partículas e não fótons, é comum utilizá-los para o poder dos cristais de interagirem com os fótons de $511 \mathrm{keV}$.
} 
onde T, S e R são as coincidências verdadeiras, espalhadas e aleatórias, respectivamente. A constante $\alpha$ é a fração de projeção que é ocupada pelo objeto a ser imageado. A constante b é igual a 1 se o método singles é usado para estimativa de aleatórios e, 2 se for utilizada a janela delayed[1], descrito na seção 2.4 .

O NEC máximo é a taxa de contagem ótima para cada sistema PET. Para sistemas PET 2D, os septos, entre os detectores, reduzem significativamente a contribuição das coincidências aleatórias e espalhadas, de tal forma que o NEC é equivalente as taxas de contagens de coincidências verdadeiras. Portanto, para este tipo de sistema, o NEC aumenta quase que linearmente com o aumento da atividade e não há uma taxa de contagem ou atividade ideal [11].

Já para os sistemas PET, com aquisição 3D, as taxas de contagens de coincidências verdadeiras e espalhadas são proporcionais a taxa de atividade, enquanto as coincidências aleatórias são proporcionais ao quadrado da atividade. Assim, existe uma taxa de atividade ótima bem definida para sistemas PET 3D, que é o ponto máximo da curva NEC[11]. Um exemplo das taxas de contagens obtidas por um sistema com BGO em modo 2D é mostrado na Figura 15.

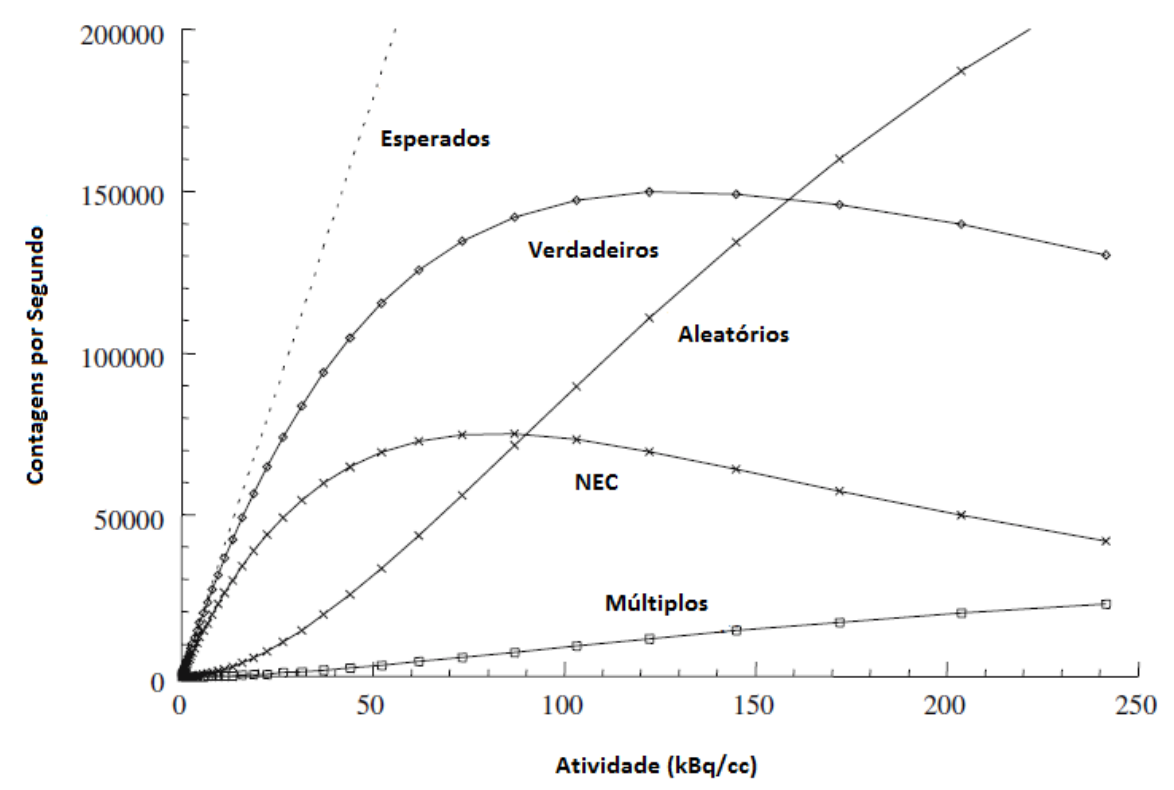

Figura 15: Curvas referentes às taxas de contagens. São mostradas as curvas para coincidências verdadeiras, aleatórias e múltiplas. Também é apresentada a curva da taxa de contagem de ruído equivalente (NEC). Estes dados foram registrados no sistema PET CTI ECAT 953B usando um cilindro de $20 \mathrm{~cm}$ de diâmetro com ${ }^{11} \mathrm{C}$ preenchido com água. Imagem adaptada do livro Positron Emission Tomography (Dale L. Bailey, et al). 
Em atividades mais elevadas, o NEC diminui porque a taxa de coincidências aleatórias aumenta aproximadamente com o quadrado da atividade e, também, devido as perdas por tempo morto[1].

São necessários alguns cuidados ao comparar os NECs de vários sistemas, tais como: a fração de espalhamento que foi utilizada e como foi determinada, entre outros cuidados[14].

\subsubsection{Fração de Espalhamento}

Fração de espalhamento é definida como a fração do total de coincidências, registradas na janela de fotopico, que foram espalhadas. O espalhamento pode ser de ambos os fótons de aniquilação, mas predomina-se o espalhamento de um fóton apenas. O espalhamento pode ocorrer dentro do objeto que contém radionuclídeo, no interior dos detectores, bem como, ou ainda, fora dos componentes do gantry, tais como os septos e os protetores laterais.

O espalhamento em sistemas PET 2D, costuma ser pequeno, menos de $15 \%$ do total de eventos no fotopico. Desta forma, a correção na imagem final costuma ser pequena e, portanto, frequentemente ignorada ocasionando pequenos impactos na imagem final.

Em PET 3D, ocorre um aumento significativo dos fótons espalhados e, estes, representam entre 20 e $50 \%$ dos dados. O espalhamento depende de alguns fatores, tais como: tamanho do objeto, densidade, ângulo de aceitação, distribuição do radiofármaco, configurações dos discriminadores de energia e do método de aquisição.

\subsubsection{Sensibilidade}

A sensibilidade do PET, assim como todos os dispositivos de imagens, é determinada, primeiramente, pela eficiência de absorção do sistema de detecção, bem como o ângulo sólido que cobre o objeto imageado[11], uma vez que, se um fóton de aniquilação é interceptado pelo anel, garante-se que o segundo fóton está viajando na direção correta e, também, será interceptado.

A taxa de coincidência real, $R_{\text {real, }}$ para uma fonte emitindo pósitron, localizada em um meio absorvedor entre um par de detectores de coincidências é dado por: 


$$
R_{\text {real }}=E \epsilon^{2} g_{A C D} e^{-\mu T}
$$

onde E é a taxa de emissão da fonte (pósitrons/seg); $\epsilon$ é a eficiência intrínseca de cada detector, isto é, a fração de fótons incidentes detectados; $\mu$ e T são coeficientes de atenuação linear e a espessura total do objeto, respectivamente; $g_{\text {ACD }}$ é a eficiência geométrica dos pares de detectores, ou seja, a fração de eventos de aniquilação em que ambos os fótons são emitidos em uma direção a ser interceptada pelo detector[1].

A máxima eficiência geométrica para ACD é obtida para uma fonte pontual localizada, precisamente, no ponto médio da linha central entre dois detectores. Contudo, este valor se altera conforme a fonte se afasta da linha central e, portanto, a eficiência geométrica é melhor representada através do cálculo da eficiência geométrica média dentro do volume do ACD, como mostra a equação abaixo:

$$
\bar{g}_{A C D} \approx 2 \times \frac{1}{3} \times\left[\frac{A_{d e t}}{\pi D^{2}}\right] \approx \frac{2 A_{d e t}}{3 \pi D^{2}}
$$

onde $\mathrm{D}$ é a distância entre os detectores e $\mathrm{A}_{\text {det }}$ é a área do detector de frente para a fonte. $\mathrm{O}$ termo entre colchetes é a eficiência geométrica de um único detector para uma fonte pontual, localizada no ponto médio da linha central entre os detectores. O fator 2 é devido a utilização de 2 detectores e o fator $1 / 3$ é a eficiência geométrica média através do volume sensível ao plano médio[1].

Para um anel de detecção de profundidade (d) e diâmetro (D), sem levar em consideração a pequena área entre os detectores, a eficiência geométrica (g) diminui linearmente de acordo com a relação d/D com o deslocamento da fonte do centro em direção a extremidade do anel, mas ainda estando no plano central, no qual a eficiência geométrica média pode ser descrita por[11]:

$$
\overline{\mathrm{g}}_{\mathrm{ACD}} \approx \frac{\mathrm{d}}{2 \mathrm{D}}
$$

A eficiência geométrica varia um pouco em todo o FOV útil do anel detector, porque, o ângulo sólido para detecção das coincidências varia com a posição da fonte.

Há também efeitos geométricos causados pela diferença no ângulo de incidência dos fótons nos detectores e pelos espaços entre os detectores. É importante frisar que, por segmentar grandes detectores em elementos menores e operá-los em coincidência com 
múltiplos detectores, é possível aumentar a resolução espacial no PET com uma pequena perda na eficiência geométrica. Este efeito é verificado na equação 12, em que a eficiência geométrica depende do diâmetro do anel, D, mas não da largura dos detectores[1].

A maior parte da perda de sensibilidade ocorre devido à necessidade dos espaçamentos dos elementos de detecção e a blindagem dos detectores, que é em torno de 0,2 a 0,3 mm. A sensibilidade em sistemas PET, também depende da eficiência intrínseca do detector $(\epsilon)$. Esta eficiência é dada pela equação:

$$
\epsilon=1-e^{\mu_{l} x}
$$

onde $\mu_{1}$ é o coeficiente de atenuação linear do material detector e $\mathrm{x}$ é a espessura do detector[1].

A finalidade de medir-se a sensibilidade de um tomógrafo por emissão é, principalmente, facilitar comparações em diferentes sistemas, uma vez que, quanto maior a sensibilidade, melhor a relação sinal-ruído da imagem reconstruída, uma vez desprezado os efeitos de tempo morto[14].

\subsection{Norma NEMA NU 2-2007[8]}

Uma vez realizadas as simulações em Tomografia por Emissão, faz-se necessário os testes de validação destes equipamentos virtuais. O padrão estabelecido pela Associação Americana National Electrical Manufactures Association NU 2-2007 (NEMA NU 2-2007) é utilizado para realização dos testes. O objetivo do material publicado na Norma é especificar procedimentos para avaliar o desempenho dos tomógrafos PET, tais como, Sensibilidade, Resolução Espacial, Fração de Espalhamento, NEC, entre outros.

\subsubsection{Resolução Espacial}

Resolução espacial de um sistema representa a habilidade para distinguir entre dois pontos, após a reconstrução da imagem. O objetivo deste teste é caracterizar as larguras das imagens reconstruídas de uma função de espalhamento pontual (PSF- point spread function) que mede-se através da amplitude da largura total a meia altura (FWHM) e a amplitude da 
largura total à dez por cento do ponto máximo (FWTM) Quanto menor estes valores, melhor a resolução espacial do sistema PET.

Os cálculos para resolução espacial, para ambas as geometrias são mostrados na Tabela 4.

\begin{tabular}{|c|c|c|}
\hline & Descrição & Fórmula \\
\hline \multicolumn{3}{|l|}{$\begin{array}{c}\text { A } 1 \text { cm do } \\
\text { centro }\end{array}$} \\
\hline Transversal & $\begin{array}{c}\text { Média x e y } \\
\text { para ambas as } \\
\text { posições de } \mathrm{z} \\
\text { (4 números) }\end{array}$ & $\operatorname{RES}=\left(\operatorname{RESx}_{\mathrm{x}=0, \mathrm{y}=1, \mathrm{z}=0}+\mathrm{RESy}_{\mathrm{x}=0, \mathrm{y}=1, \mathrm{z}=0}+\mathrm{RESx}_{\mathrm{x}=0, \mathrm{y}=1, \mathrm{z}=54,5}+\mathrm{RESy}_{\mathrm{x}=0, \mathrm{y}=1, \mathrm{z}=54,5}\right) / 4$ \\
\hline Axial & $\begin{array}{c}\text { Média das } 2 \\
\text { posições de } \mathrm{z} \\
\text { (2 números }\end{array}$ & $\operatorname{RES}=\left(\mathrm{RESz}_{\mathrm{x}=0, \mathrm{y}=1, \mathrm{z}=0}+\mathrm{RESz}_{\mathrm{x}=0, \mathrm{y}=1, \mathrm{z}=54,5}\right) / 2$ \\
\hline \multicolumn{3}{|l|}{$\begin{array}{l}\grave{A} 10 \mathrm{~cm} \mathrm{do} \\
\text { centro }\end{array}$} \\
\hline $\begin{array}{c}\text { Radial } \\
\text { transersa }\end{array}$ & $\begin{array}{c}\text { Média de } 2 \\
\text { transversais } \\
\text { para ambas as } \\
\text { posições de } z \\
\text { (4 números) }\end{array}$ & $\operatorname{RES}=\left(\operatorname{RESx}_{\mathrm{x}=10, \mathrm{y}=0, \mathrm{z}=0}+\mathrm{RESy}_{\mathrm{x}=0, \mathrm{y}=10, \mathrm{z}=0}+\mathrm{RESx}_{\mathrm{x}=10, \mathrm{y}=0, \mathrm{z}=54,5}+\mathrm{RESy}_{\mathrm{x}=0, \mathrm{y}=10, \mathrm{z}=54,5}\right) / 4$ \\
\hline $\begin{array}{l}\text { Tangencial } \\
\text { transversa }\end{array}$ & $\begin{array}{l}\text { Média de } 2 \\
\text { transversais } \\
\text { para ambas as } \\
\text { posições de } \mathrm{z} \\
\text { (4 números) }\end{array}$ & $\operatorname{RES}=\left(\operatorname{RESy}_{\mathrm{x}=10, \mathrm{y}=0, \mathrm{z}=0}+\mathrm{RESx}_{\mathrm{x}=0, \mathrm{y}=10, \mathrm{z}=0}+\mathrm{RESy}_{\mathrm{x}=10, \mathrm{y}=0, \mathrm{z}=54,5}+\mathrm{RESx}_{\mathrm{x}=0, \mathrm{y}=10, \mathrm{z}=54,5}\right) / 4$ \\
\hline $\begin{array}{l}\text { Resolução } \\
\text { axial }\end{array}$ & $\begin{array}{l}\text { Média de } 2 \\
\text { transversais } \\
\text { para ambas as } \\
\text { posições de } \mathrm{z} \\
\text { (4 números) }\end{array}$ & $\operatorname{RES}=\left(\mathrm{RESz}_{\mathrm{x}=10, \mathrm{y}=0, \mathrm{z}=0}+\mathrm{RESz}_{\mathrm{x}=0, \mathrm{y}=10, \mathrm{z}=0}+\mathrm{RESz}_{\mathrm{x}=10, \mathrm{y}=0, \mathrm{z}=54,5}+\mathrm{RESz}_{\mathrm{x}=0, \mathrm{y}=10, \mathrm{z}=54,5}\right) / 4$ \\
\hline
\end{tabular}

Tabela 4: Fórmulas para o cálculo da resolução espacial. Adaptada de NEMA NU 2-2007.

\subsubsection{Fração de Espalhamento, perdas de contagens e medidas de aleatórios}

Após a aniquilação elétron-pósitron, pode ocorrer o espalhamento dos fótons de aniquilação, que resulta em uma falsa localização dos eventos de coincidências detectados pelo PET. As variações dos equipamentos PETs levam a diferentes sensibilidades à radiação espalhada. As medidas de perdas de contagens e de taxas de eventos aleatórios expressam a habilidade do PET em medir fontes altamente radioativas.

Dois métodos são utilizados para análise desses parâmetros. No primeiro método mede-se as coincidências aleatórias, ou com uso da janela delayed ou através dos singles detectados. Prefere-se o primeiro método uma vez que ele permite uma estimativa da fração 
de espalhamento como uma função da taxa de contagem. O segundo método seria uma alternativa para sistemas que não possuem a capacidade de medir os eventos aleatórios.

O objetivo deste teste é medir a sensibilidade relativa dos sistemas para radiação espalhada. O espalhamento é expresso pela fração de espalhamento (SF-scatter fraction) para todo tomógrafo. O segundo objetivo é determinar os efeitos de tempo morto do sistema e gerar os eventos aleatórios para vários níveis de atividades da fonte. A taxa de eventos verdadeiros é a taxa total de eventos de coincidências menos a taxa de eventos aleatórios menos a taxa de eventos espalhados.

\subsubsection{Sensibilidade}

A sensibilidade de um sistema PET é expressa como a taxa de contagem, por segundo, que eventos de coincidências verdadeiras são detectados para determinadas fontes.

A sensibilidade sofre interferência da atenuação do meio onde se encontra a emissão de radiação. Para se chegar a uma medida de atenuação livre, medidas sucessivas são realizadas com uma fonte linear uniforme cercada de absorvedores conhecidos.

O objetivo deste procedimento é medir a sensibilidade ou a habilidade dos tomógrafos em detectar os pósitrons. 


\section{Metodologia}

Para avaliação do desempenho do sistema de tomografia PET, com geometria elipsoidal, utilizou-se o GATE versão 6.1 para montagem das geometrias e todas as demais características necessárias aos sistemas PET, e posterior realização das simulações. A obtenção das saídas de respostas foram feitas através do ROOT. Todas as simulações foram realizadas utilizando um conjunto de clusters, presentes no CIRP da Universidade de São Paulo, campus de Ribeirão Preto.

Os cálculos referentes às posições e ângulos dos blocos de cristais, para criação da geometria elíptica, do sistema PET, foram feitos através do Excell e para implementação das contas e análise dos testes de validação exigidos pela norma NEMA NU 2-2007 utilizou-se o programa MatLab 2011.

Para comparação dos resultados construiu-se dois sistemas PET com diferentes geometrias. O primeiro sistema foi construído com geometria convencional dos sistemas PET atuais, neste caso, com os cristais arranjados em forma circular. Para o segundo sistema, a construção deu-se em forma diferenciada, onde os cristais foram arranjados em forma elipsoidal.

Todos os demais parâmetros foram mantidos, tanto na forma circular quanto elipsoidal para comparação e análise dos resultados obtidos, com exceção do número de detectores, onde houve a necessidade de redução para montagem da geometria elipsoidal.

Uma vez realizadas as simulações, os resultados obtidos foram calculados conforme as especificações fornecidas na norma NEMA NU 2-2007.

Tanto na geometria cilíndrica quanto elíptica, o material utilizado para a blindagem foi o chumbo, cobrindo-se as laterais dos blocos de cristais.

\subsection{Construção da Geometria do Sistema PET}

\subsubsection{Geometria Circular}

O primeiro sistema PET foi construído com uma grade de cristal de LSO 13 x 13, onde cada cristal é de 4 × 4 × $20 \mathrm{~mm}^{3}$ e com seção transversal de 54 x $54 \mathrm{~mm}^{2}$. O sistema está 
arranjado em forma circular, com 4 anéis[2], onde cada anel contem 46 blocos de cristais, totalizando 184 blocos. Na direção transaxial, os detectores opostos estão separados a uma distância de 816,4 mm.

Para construção da geometria circular, criou-se o primeiro bloco no qual foi inserido os cristais em seu interior. Em seguida, utilizou-se um comando no GATE, o ring repeater, e este bloco foi replicado em torno de todo o anel. O ring repeater torna possível repetir um volume ao longo do anel, sendo assim, útil para construir um anel de detectores em sistemas PET[6]. Portanto, uma vez construído o primeiro detector, montou-se o sistema PET, em forma circular, contendo 46 blocos de cristais em cada anel utilizando-se este comando.

\subsubsection{Geometria Elíptica}

O segundo sistema PET foi construído com uma grade de cristal de LSO 13 x 13, onde cada cristal é de $4 \times 4 \times 20 \mathrm{~mm}^{3}$ e com seção transversal de 54 x $54 \mathrm{~mm}^{2}$. O sistema está arranjado em forma elipsoidal, com 4 anéis[2], onde cada anel contem 36 blocos de cristais, totalizando 144 blocos. Na horizontal, os detectores estão separados a uma distância de 816,4 mm e na vertical, estão separados a uma distância de 500 mm.

Para geometria elíptica, criou-se o primeiro bloco, mas não há no GATE um comando que os replique formando esta geometria. O generic repeater permite repetir o volume de acordo com uma lista de transformações (rotação e translação). Isto permite movimentar os blocos de cristais da maneira que for conveniente para adequá-los a montagem da nova geometria desejada. A posição do volume na geometria é definido utilizando-se o placement (localização). Três tipos de localizadores (placement) estão disponíveis: translação, rotação e alinhamento[6].

Portanto, a montagem da estrutura elíptica foi feita bloco a bloco com o uso do generic repeatear após serem encontrados a posição e o ângulo de cada detector, utilizando-se cálculos de geometria analítica para elipse. 


\subsubsection{Sinogramas}

Como descrito na seção 2.5, os eventos de coincidências em um sistema PET são organizados em uma matriz 2D conhecida como sinograma.

As coincidências, para ambas as geometrias, foram criadas através do segundo método descrito na seção 2.4. Este método foi implementado no ROOT, de acordo com as especificações para cada geometria proposta, tais como suas dimensões.

A obtenção dos sinogramas, para ambas geometrias, deu-se através da elaboração de um código ROOT levando em consideração as posições dos cristais, em cada bloco. Os sinogramas obtidos, foram posteriormente utilizados para todos os testes de validação propostos neste projeto.

\subsection{Sensibilidade}

Conforme exigido pela norma NU 2-2007, criou-se no GATE um conjunto de cinco coberturas de alumínios concêntricos que foram utilizados[16] para os teste de sensibilidade, conforme mostrado na Figura 16.

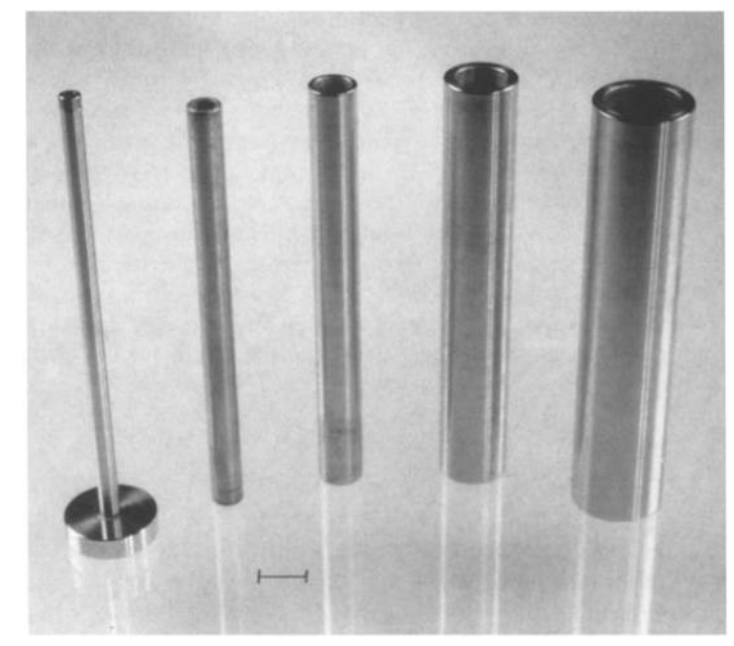

Figura 16: Coberturas de alumínio para o teste de sensibilidade. Imagem retirada de "A method for measuring the absolute sensitivity of positron emission tomography scanners" ( Bailey, D. L., et al). 
Um tubo de polietileno de $700 \pm 5 \mathrm{~mm}$ foi preenchido com cerca de $4 \pm 10 \% \mathrm{MBq}$ de ${ }^{18} \mathrm{~F}$ e, posteriormente, inserido no interior das coberturas de mesmo comprimento do tubo, com ambas extremidades seladas. O phantom ficou suspenso no centro do FOV transaxial, alinhado com os eixos do tomógrafo de tal maneira que qualquer mecanismo de apoio é externo ao FOV.

Foram realizados cinco aquisições de dados com diferentes atenuações, que foram gerados adicionando-se as coberturas de alumínio, uma a uma. O tempo de cada aquisição foi de $400 \mathrm{~s}$ [13]. Os experimentos foram repetidos posteriormente com o phantom deslocado à $10 \mathrm{~cm}$ do centro do FOV transaxial.

Estes procedimentos foram realizados para ambas as geometrias. As medidas referentes as coberturas de alumínio, para este teste, são mostradas na Tabela 5.

\begin{tabular}{|c|c|c|c|}
\hline Cobertura & Diâmetro Interno $(\mathbf{m m})$ & Diâmetro Externo $\mathbf{( m m})$ & Comprimento $(\mathbf{m m})$ \\
\hline 1 & 3.9 & 6.4 & 700 \\
\hline 2 & 7.0 & 9.5 & 700 \\
\hline 3 & 10.2 & 12.7 & 700 \\
\hline 4 & 13.4 & 15.9 & 700 \\
\hline 5 & 16.6 & 19.1 & 700 \\
\hline
\end{tabular}

Tabela 5: Medidas das coberturas de alumínio usadas para o teste de sensibilidade de acordo com NEMA NU 22007. Fonte (NEMA NU 2-2007).

\subsection{Resolução Espacial}

$\mathrm{O}$ teste de resolução espacial foi realizado criando-se uma fonte pontual contendo ${ }^{18} \mathrm{~F}$, conforme especificados pela NEMA NU 2-2007. A atividade foi de $4 \mathrm{MBq}$ e o tempo de aquisição de $200 \mathrm{~s}$ para ambas as geometrias.

Os dados foram adquiridos em três posições transaxiais $(\mathrm{x}, \mathrm{y})$, onde $\mathrm{x}$ e y são os eixos no plano transaxial $(0,1),(10,0)$ e $(0,10)$. Essas medidas foram realizadas em duas posições axiais (z) dentro do FOV do PET: a primeira no centro do FOV e a segunda deslocada $1 / 4$ do centro do FOV $(54.5 \mathrm{~mm})$, totalizando 6 medidas para cada geometria proposta.

A Figura 17 representa as diferentes posições da fonte para o teste de resolução espacial. 


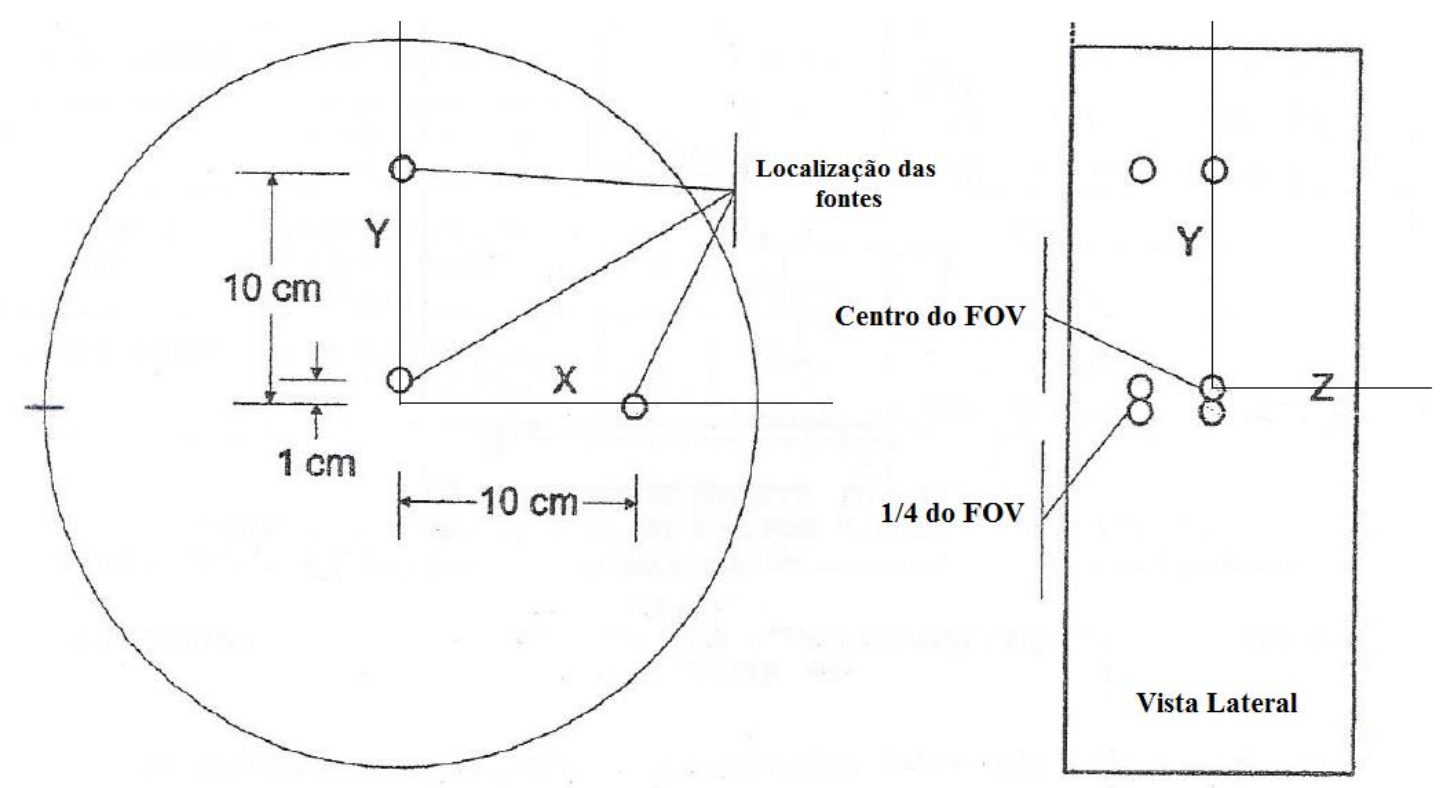

Figura 17: Representação das diferentes posições da fonte para as medidas de resolução espacial. Imagem adaptada de NEMA NU 2-2007.

\subsection{Fração de Espalhamento e NEC}

A fração de espalhamento e a taxa NEC foram calculados a partir da estimativa do desempenho da taxa de contagem[13]. Para tais medidas, utilizou-se um phantom cilíndrico de $700 \pm 5 \mathrm{~mm}$ de comprimento com diâmetro externo de $203 \pm 3 \mathrm{~mm}$ (22 litros). A fonte linear foi inserida axialmente no cilindro a uma distância radial de $45 \pm 1 \mathrm{~mm}$ abaixo do centro do phantom (NEMA phantom).

Para este teste foram realizadas 33 simulações para cada geometria, variando-se a atividade e o tempo de cada aquisição conforme mostrado na Tabela 6Tabela 6: 


\begin{tabular}{|c|c|}
\hline Tempo (s) & Atividade (MBq) \\
\hline 0.750 & 1033.4 \\
\hline 0.750 & 881.91 \\
\hline 1.125 & 751.95 \\
\hline 1.500 & 641.45 \\
\hline 1.875 & 546.94 \\
\hline 1.875 & 466.32 \\
\hline 1.875 & 398.21 \\
\hline 2.250 & 339.14 \\
\hline 2.250 & 289.80 \\
\hline 2.625 & 246.71 \\
\hline 3.000 & 210.57 \\
\hline 3.000 & 180.00 \\
\hline 3.375 & 153.59 \\
\hline 3.750 & 131.35 \\
\hline 4.125 & 112.10 \\
\hline 4.875 & 95.322 \\
\hline 5.250 & 81.897 \\
\hline 6.000 & 69.076 \\
\hline 6.750 & 58.915 \\
\hline 7.875 & 50.187 \\
\hline 9.375 & 42.823 \\
\hline 10.500 & 36.481 \\
\hline 12.000 & 31.162 \\
\hline 12.000 & 26.526 \\
\hline 12.750 & 22.639 \\
\hline 15.000 & 19.298 \\
\hline 16.875 & 16.502 \\
\hline 18.000 & 14.047 \\
\hline 19.500 & 12.001 \\
\hline 21.000 & 10.228 \\
\hline 22.500 & 8.7282 \\
\hline 30.000 & 4.35 \\
\hline 30.000 & 0 \\
\hline
\end{tabular}

Tabela 6: Valores dos tempos e atividades utilizados para os testes de Fração de Espalhamento e NECR.

O teste da fração de espalhamento é feito em baixa atividade, conforme especificações da norma NEMA NU 2-2007, sendo neste caso de 4.35 MBq. 


\section{Resultados}

\subsubsection{Geometria Circular}

O sistema PET, para geometria circular, está representado na Figura 18:

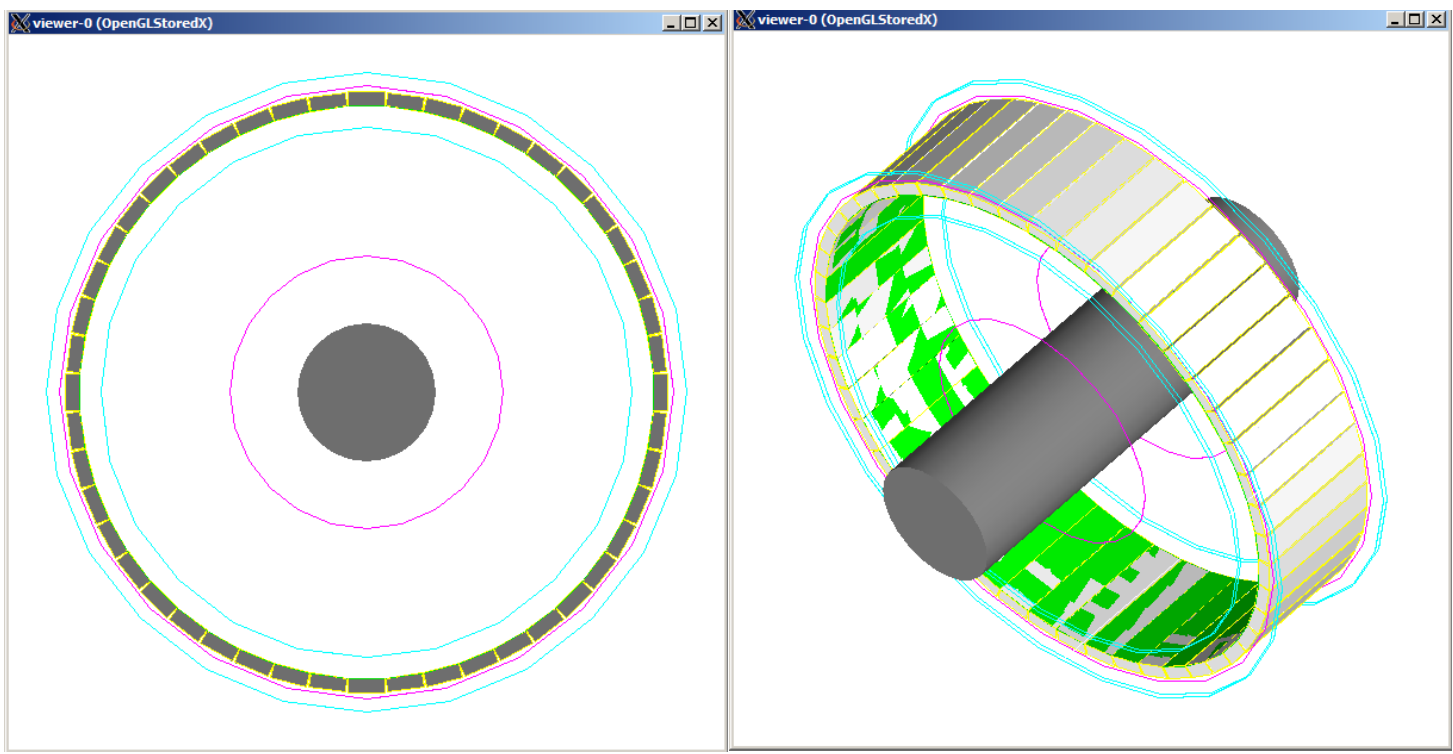

Figura 18: Sistema PET em geometria circular.

\subsubsection{Geometria Elíptica}

O sistema PET, para geometria elíptica, está representado na Figura 19:

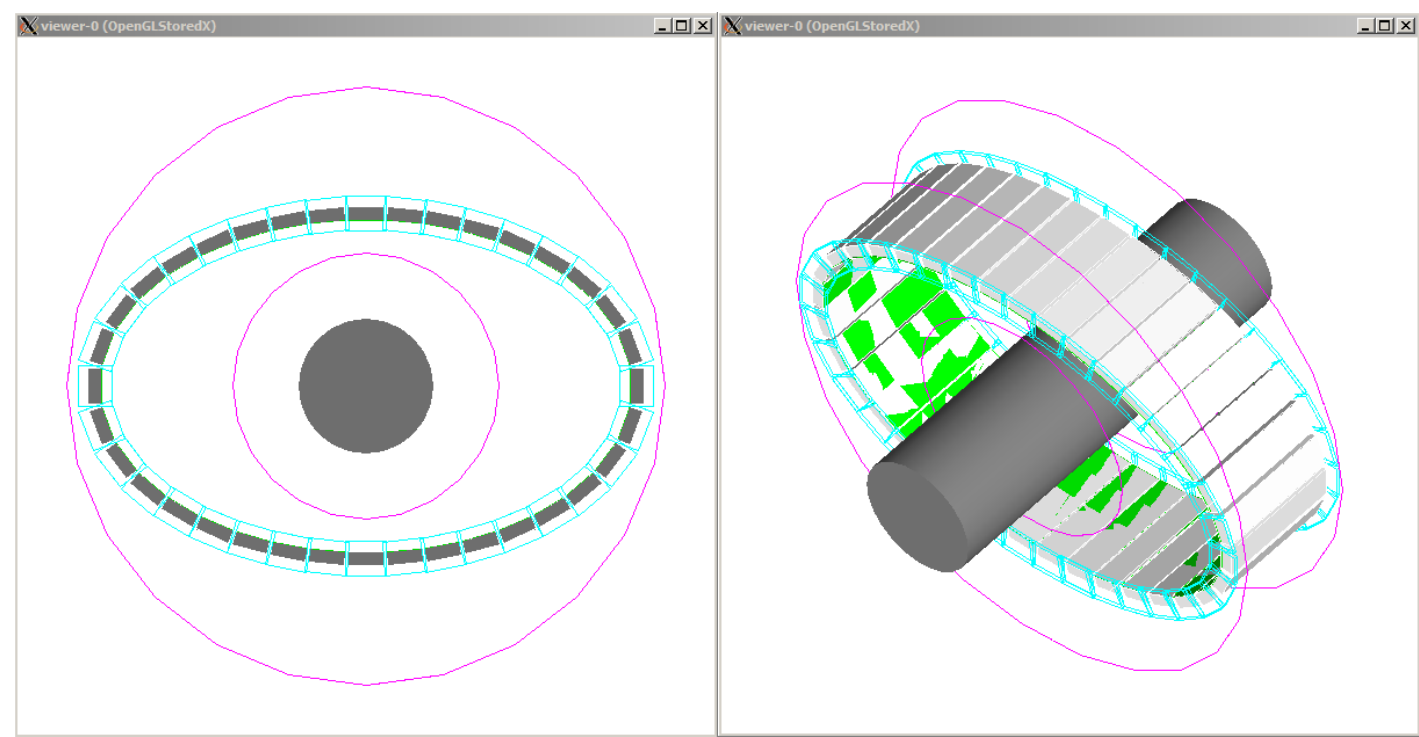

Figura 19: Sistema PET em geometria elíptica. 
O sistema elíptico com os blocos de cristais posicionados com suas faces voltadas para o centro do FOV estão representados na Figura 20.

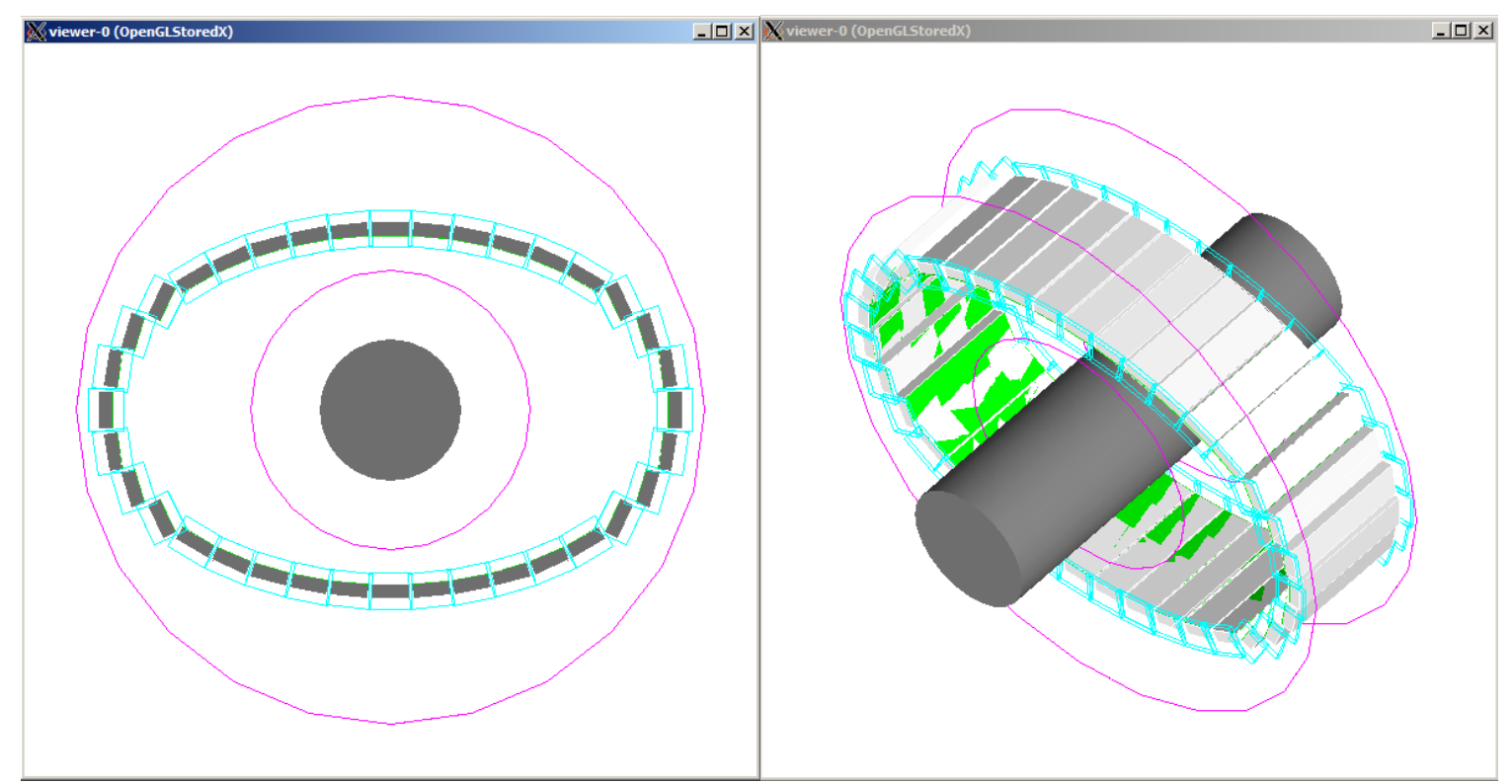

Figura 20: Sistema PET em geometria elíptica com os blocos posicionados com suas faces voltadas para o centro do FOV.

As figuras 18 e 19 e 20 foram obtidas através do visualizador do GATE, o qual possibilita, inclusive, o movimento do sistema, proporcionando visões em diferentes ângulos e posições.

\subsubsection{Sinogramas}

Os sinogramas obtidos estão representados nas figuras 21 e 22: 


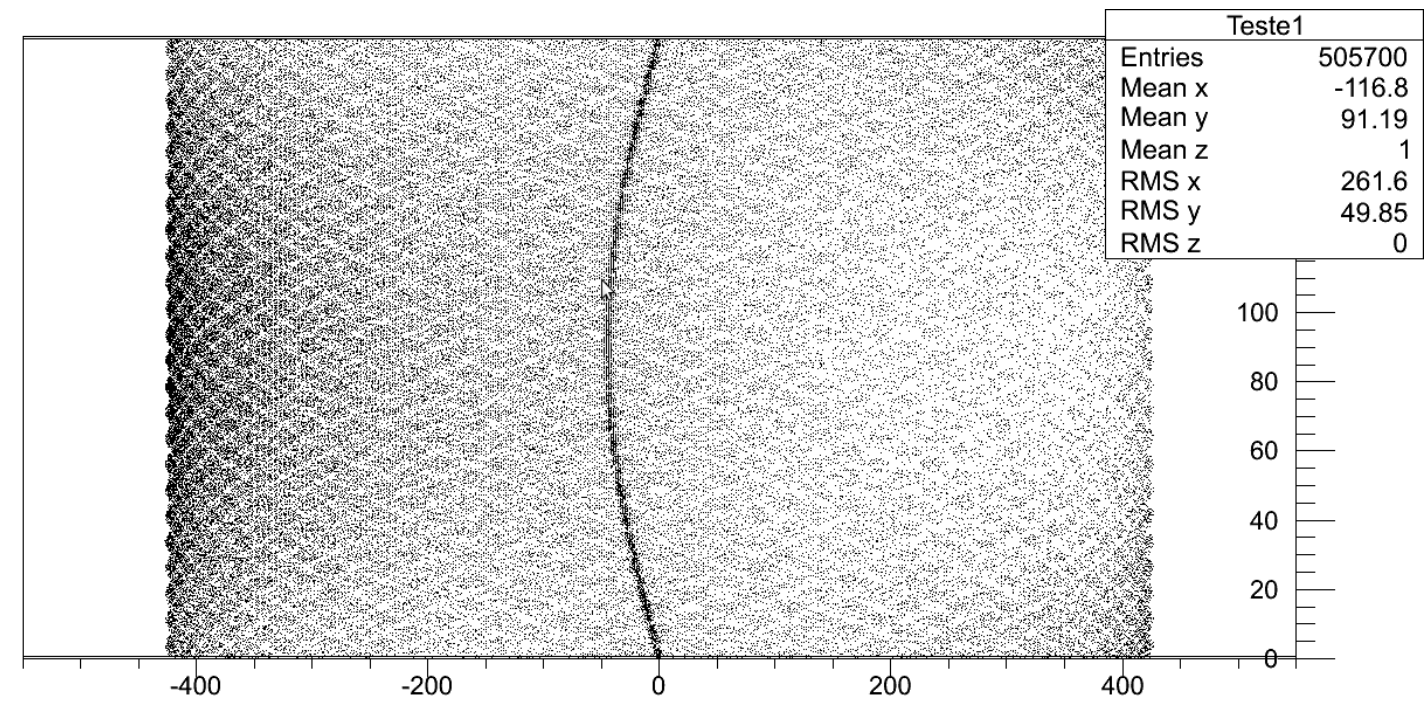

Figura 21: Representação do sinograma obtido para o sistema PET cilíndrico.

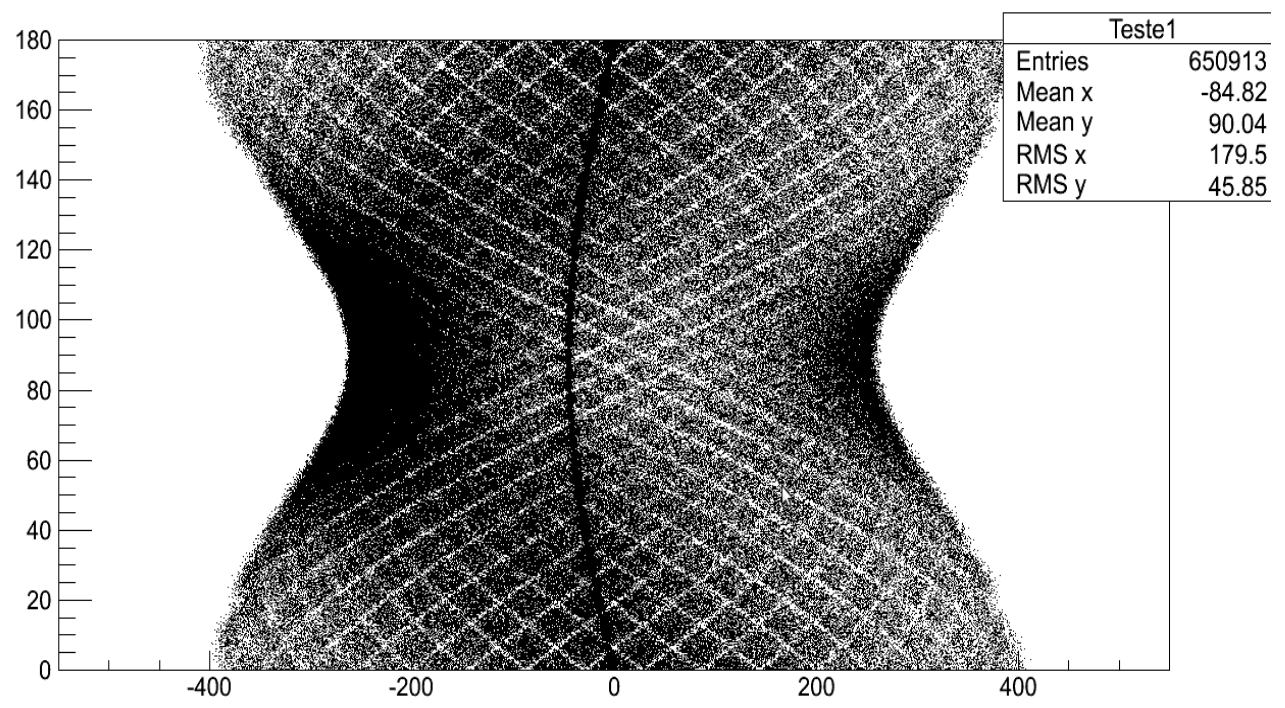

Figura 22: Representação do sinograma obtido para o sistema PET elíptico.

\subsection{Sensibilidade}

A sensibilidade do sistema PET cilíndrico, com o phantom localizado no centro do FOV é 14,77 kcps/MBq e para o sistema elíptico, a sensibilidade é de 19,01 kcps/MBq. Já para o phantom à $10 \mathrm{~cm}$ do centro, a sensibilidade do sistema PET cilindrico foi de 15,34 kcps/MBq, enquanto que, para o sistema PET elíptico a sensibilidade, com o phantom localizado nesta posição foi de 19,35 kcps/MBq. 
A curva da sensibilidade, para ambas as geometrias, com o phantom localizado no centro do sistema PET é mostrada na Figura 23.
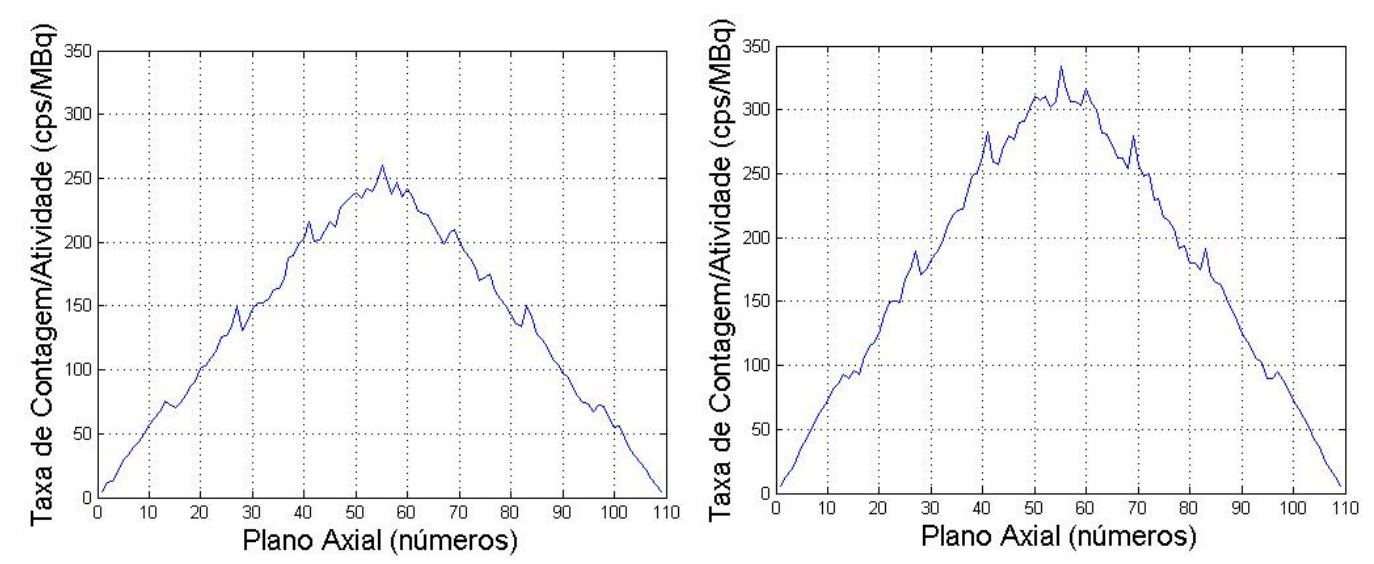

Figura 23: Perfil de Sensibilidade para ambas as geometrias com as coberturas de alumínio localizadas no centro do sistema. A figura da esquerda representa a sensibilidade do sistema PET circular, enquanto a figura da direita representa a sensibilidade do sistema PET elipsoidal.

A curva da sensibilidade, para ambas as geometrias, com o phantom localizado à 10 cm do centro do sistema PET é mostrada na Figura 24.
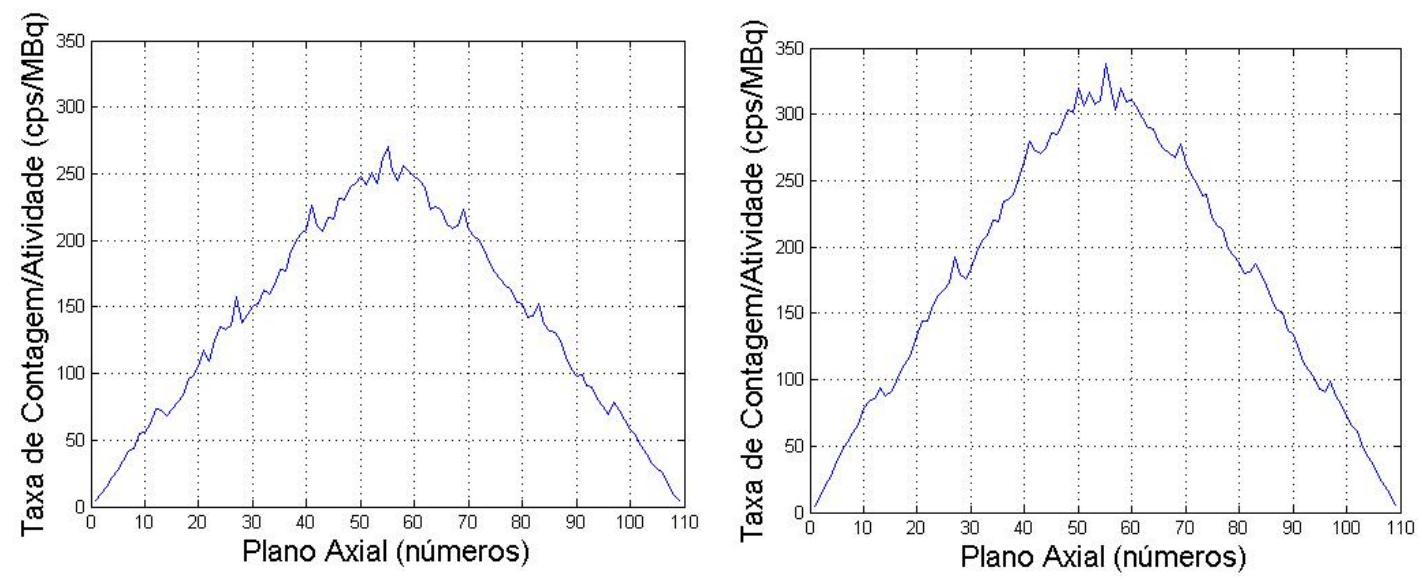

Figura 24: Perfil de Sensibilidade para ambas as geometrias com as coberturas de alumínio localizadas a $10 \mathrm{~cm}$ do sistema. A figura da esquerda representa a sensibilidade do sistema PET circular, enquanto a figura da direita representa a sensibilidade do sistema PET elipsoidal.

A sensibilidade do sistema PET, elipsoidal, utilizando-se uma fonte linear, teve um ganho de $28,7 \%$ em relação ao sistema circular, com o phantom posicionado no centro $(0 \mathrm{~cm})$ 
do FOV. Para o phantom deslocado $10 \mathrm{~cm}$ do centro do FOV, a sensibilidade do sistema PET elíptico foi superior em $26,2 \%$ comparado ao sistema circular.

\subsection{Resolução Espacial}

As tabelas 7, 8, 9 e 10 são referentes aos testes de resolução espacial, para ambas as geometrias. Os blocos de cristais, do sistema elíptico são posicionados tangentes a elípse. Para estes testes, uma fonte pontual foi inserida em um phantom (Nema phantom).

Uma vez que os resultados, para resolução espacial do sistema elíptico, ficaram aquém do que esperava-se, fez-se o reposicionamento de alguns blocos de cristais, na estrutura elíptica, no qual modificou-se os ângulos destes blocos de tal forma que a face dos detectores foram direcionadas para o centro do FOV do sistema PET. Para estas novas simulações as fontes foram inseridas em um capilar de vidro. Os resultados para resolução espacial, de ambos os sistema, cilíndrico e elíptico são mostrados nas tabelas 11, 12, 13 e 14 .

Os resultados acompanhados por (*) representam melhora na resolução espacial, do sistema elíptico, quando comparados ao sistema cilíndrico.

A Tabela 7 mostra os valores obtidos, para FWHM e FWTM, no eixo x, para todas as diferentes posições da fonte.

\begin{tabular}{|c|c|c|c|c|c|}
\hline \multicolumn{6}{|c|}{ Direção X } \\
\hline \multirow{2}{*}{$\begin{array}{l}\text { Posições Axiais } \\
\text { (z) }\end{array}$} & \multirow{2}{*}{$\begin{array}{c}\text { Posições transaxiais } \\
\qquad(x, y)\end{array}$} & \multicolumn{2}{|c|}{$\begin{array}{c}\text { FWHM } \\
(\mathbf{m m})\end{array}$} & \multicolumn{2}{|c|}{$\begin{array}{c}\text { FWTM } \\
(\mathbf{m m})\end{array}$} \\
\hline & & Cilíndrico & Elíptico & Cilíndrico & Elíptico \\
\hline \multirow{3}{*}{ Centro do FOV } & $(0,1)$ & 7,08 & 7,60 & 34,86 & $\mathbf{3 7 , 8 3}$ \\
\hline & $(0,10)$ & 33,03 & 65,83 & 250,44 & - \\
\hline & $(10,0)$ & 5,44 & $* 5,00$ & 11,39 & $* 10,84$ \\
\hline \multirow{3}{*}{$1 / 4$ do FOV } & $(0,1)$ & 6,72 & 6,88 & 30,07 & $* 27,55$ \\
\hline & $(0,10)$ & 24,54 & 55,73 & 186,21 & 641,67 \\
\hline & $(10,0)$ & 5,68 & $* 5,13$ & 11,62 & $* 11,14$ \\
\hline
\end{tabular}

Tabela 7: Valores da FWHM e FWTM na direção X. ( - ) Não foi possível obter valores em FWTM nesta posição. 
A Tabela 8 mostra os valores obtidos, para FWHM e FWTM, no eixo y, para todas as diferentes posições da fonte.

\begin{tabular}{|c|c|c|c|c|c|}
\hline \multicolumn{6}{|c|}{ Direção Y } \\
\hline \multirow{2}{*}{$\begin{array}{l}\text { Posições Axiais } \\
\text { (z) }\end{array}$} & \multirow{2}{*}{$\begin{array}{c}\text { Posições transaxiais } \\
(\mathbf{x}, \mathbf{y})\end{array}$} & \multicolumn{2}{|c|}{$\begin{array}{c}\text { FWHM } \\
(\mathbf{m m})\end{array}$} & \multicolumn{2}{|c|}{$\begin{array}{c}\text { FWTM } \\
(\mathbf{m m})\end{array}$} \\
\hline & & Cilíndrico & Elíptico & Cilíndrico & Elíptico \\
\hline \multirow{3}{*}{ Centro do FOV } & $(0,1)$ & 6,26 & 8,07 & 26,63 & 35,34 \\
\hline & $(0,10)$ & 5,41 & $\mathbf{7 , 5 1}$ & 11,25 & 15,51 \\
\hline & $(10,0)$ & 32,63 & $* 32,08$ & 229,57 & 239,63 \\
\hline \multirow{3}{*}{$1 / 4$ do FOV } & $(0,1)$ & 6,52 & 8,28 & 28,89 & 37,25 \\
\hline & $(0,10)$ & 5,39 & 7,90 & 11,55 & 16,17 \\
\hline & $(10,0)$ & 25,63 & 27,49 & 172,32 & 190,59 \\
\hline
\end{tabular}

Tabela 8: Valores da FWHM e FWTM na direção Y.

A Tabela 9 mostra os valores obtidos, para FWHM e FWTM, no eixo z, para todas as diferentes posições da fonte.

\begin{tabular}{|c|c|c|c|c|c|}
\hline \multicolumn{6}{|c|}{ Direção Z } \\
\hline \multirow{2}{*}{$\begin{array}{l}\text { Posições Axiais } \\
(\mathrm{z})\end{array}$} & \multirow{2}{*}{$\begin{array}{c}\text { Posições transaxiais } \\
\qquad(\mathbf{x}, \mathbf{y})\end{array}$} & \multicolumn{2}{|c|}{$\begin{array}{c}\text { FWHM } \\
(\mathbf{m m})\end{array}$} & \multicolumn{2}{|c|}{$\begin{array}{c}\text { FWTM } \\
(\mathbf{m m})\end{array}$} \\
\hline & & Cilíndrico & Elíptico & Cilíndrico & Elíptico \\
\hline \multirow{3}{*}{ Centro do FOV } & $(0,1)$ & 3,68 & 5,07 & 7,99 & 10,93 \\
\hline & $(0,10)$ & 7,42 & 11,61 & 29,20 & 56,18 \\
\hline & $(10,0)$ & 7,15 & $* 5,57$ & 30,12 & $* 18,34$ \\
\hline \multirow{3}{*}{$1 / 4$ do FOV } & $(0,1)$ & $\mathbf{3 , 5 3}$ & 3,91 & 7,38 & 8,24 \\
\hline & $(0,10)$ & 6,14 & 11,23 & 17,89 & 42,88 \\
\hline & $(10,0)$ & 6,07 & $* 4,77$ & 17,99 & $* 13,47$ \\
\hline
\end{tabular}

Tabela 9: Valores da FWHM e FWTM na direção Z. 
A Tabela 10 mostra os resultados, para o teste de resolução espacial, para ambas as geometrias, circular e elíptica. Os valores foram obtidos calculando-se as médias nos três eixos de coordenadas $(\mathrm{x}, \mathrm{y}, \mathrm{z})$ para cada posição.

\begin{tabular}{|c|c|c|c|c|c|}
\hline \multirow{2}{*}{$\begin{array}{l}\text { Posições Axiais } \\
\text { (z) }\end{array}$} & \multirow{2}{*}{$\begin{array}{l}\text { Posições transaxiais } \\
\qquad(\mathbf{x}, \mathbf{y})\end{array}$} & \multicolumn{2}{|c|}{$\begin{array}{c}\text { FWHM } \\
(\mathbf{m m})\end{array}$} & \multicolumn{2}{|c|}{$\begin{array}{c}\text { FWTM } \\
(\mathbf{m m})\end{array}$} \\
\hline & & Cilindrico & Elíptico & Cilindrico & Elíptico \\
\hline \multirow{3}{*}{ Centro do FOV } & $(0,1)$ & 5,68 & 6,92 & 23,16 & 28,02 \\
\hline & $(0,10)$ & 15,28 & 28,34 & 20,22 & 35,84 \\
\hline & $(10,0)$ & 15,08 & $* 14,20$ & 90,36 & $* 89,60$ \\
\hline \multirow{3}{*}{$1 / 4$ do FOV } & $(0,1)$ & 5,58 & 6,36 & 22,06 & 24,35 \\
\hline & $(0,10)$ & 12,02 & 24,96 & 71,88 & 233,58 \\
\hline & $(10,0)$ & 12,46 & 12,46 & 67,32 & 71,74 \\
\hline
\end{tabular}

Tabela 10: Resultado da resolução espacial para os sistemas PET cilíndrico e elíptico.

A Tabela 11 mostra os valores obtidos, para FWHM e FWTM, no eixo x, para todas as diferentes posições da fonte.

\begin{tabular}{|c|c|c|c|c|c|}
\hline \multicolumn{6}{|c|}{ Direção X } \\
\hline \multirow{2}{*}{$\begin{array}{l}\text { Posições Axiais } \\
\text { (z) }\end{array}$} & \multirow{2}{*}{$\begin{array}{l}\text { Posições transaxiais } \\
(\mathbf{x}, \mathbf{y})\end{array}$} & \multicolumn{2}{|c|}{$\begin{array}{c}\text { FWHM } \\
(\mathrm{mm})\end{array}$} & \multicolumn{2}{|c|}{$\begin{array}{c}\text { FWTM } \\
(\mathbf{m m})\end{array}$} \\
\hline & & Cilíndrico & Elíptico & Cilíndrico & Elíptico \\
\hline \multirow{3}{*}{ Centro do FOV } & $(0,1)$ & 7,49 & 7,76 & 35,52 & $* 33,80$ \\
\hline & $(0,10)$ & 16,22 & 19,87 & 144,71 & 221,39 \\
\hline & $(10,0)$ & 6,85 & $* 6,20$ & 19,38 & $* 16,36$ \\
\hline \multirow{3}{*}{$1 / 4$ do FOV } & $(0,1)$ & 7,31 & 7,35 & 33,34 & $* 29,30$ \\
\hline & $(0,10)$ & 13,34 & 16,49 & 97,11 & 145,14 \\
\hline & $(10,0)$ & 7,07 & $* 6,51$ & 21,71 & $* 17,87$ \\
\hline
\end{tabular}

Tabela 11: Valores da FWHM e FWTM na direção X. 
A Tabela 12 mostra os valores obtidos, para FWHM e FWTM, no eixo y, para todas as diferentes posições da fonte.

\begin{tabular}{|c|c|c|c|c|c|}
\hline \multicolumn{6}{|c|}{ Direção Y } \\
\hline \multirow{2}{*}{$\begin{array}{l}\text { Posições Axiais } \\
\text { (z) }\end{array}$} & \multirow{2}{*}{$\begin{array}{c}\text { Posições transaxiais } \\
\qquad(\mathbf{x}, \mathbf{y})\end{array}$} & \multicolumn{2}{|c|}{$\begin{array}{c}\text { FWHM } \\
(\mathbf{m m})\end{array}$} & \multicolumn{2}{|c|}{$\begin{array}{c}\text { FWTM } \\
(\mathbf{m m})\end{array}$} \\
\hline & & Cilíndrico & Elíptico & Cilíndrico & Elíptico \\
\hline \multirow{3}{*}{ Centro do FOV } & $(0,1)$ & 7,08 & 8,79 & 31,66 & 38,68 \\
\hline & $(0,10)$ & 6,55 & 9,31 & 18,54 & 31,87 \\
\hline & $(10,0)$ & 18,30 & 19,76 & 139,67 & $* 130,30$ \\
\hline \multirow{3}{*}{$1 / 4$ do FOV } & $(0,1)$ & 7,17 & 9,32 & 31,91 & 42,12 \\
\hline & $(0,10)$ & 6,78 & 9,62 & 21,16 & 34,64 \\
\hline & $(10,0)$ & 14,95 & 15,69 & 96,01 & $* 90,91$ \\
\hline
\end{tabular}

Tabela 12: Valores da FWHM e FWTM na direção Y.

A Tabela 13 mostra os valores obtidos, para FWHM e FWTM, no eixo z, para todas as diferentes posições da fonte.

\begin{tabular}{|c|c|c|c|c|c|}
\hline \multicolumn{6}{|c|}{ Direção Z } \\
\hline \multirow{2}{*}{$\begin{array}{l}\text { Posições Axiais } \\
\text { (z) }\end{array}$} & \multirow{2}{*}{$\begin{array}{c}\text { Posições transaxiais } \\
\qquad(x, y)\end{array}$} & \multicolumn{2}{|c|}{$\begin{array}{c}\text { FWHM } \\
(\mathbf{m m})\end{array}$} & \multicolumn{2}{|c|}{$\begin{array}{c}\text { FWTM } \\
(\mathbf{m m})\end{array}$} \\
\hline & & Cilíndrico & Elíptico & Cilíndrico & Elíptico \\
\hline \multirow{3}{*}{ Centro do FOV } & $(0,1)$ & 5,27 & 6,34 & 11,84 & 14,15 \\
\hline & $(0,10)$ & 14,42 & 41,68 & 40,15 & 63,06 \\
\hline & $(10,0)$ & 14,07 & $* 10,06$ & 40,58 & $* 34,14$ \\
\hline \multirow{3}{*}{$1 / 4$ do FOV } & $(0,1)$ & 4,61 & 4,99 & 11,19 & 11,73 \\
\hline & $(0,10)$ & 11,34 & 32,47 & 28,82 & 52,56 \\
\hline & $(10,0)$ & 11,55 & $* 8,22$ & 29,04 & $* 23,63$ \\
\hline
\end{tabular}

Tabela 13: Valores da FWHM e FWTM na direção Z. 
A Tabela 14 representa os resultados, para o teste de resolução espacial, para ambas as geometrias, circular e elíptica com os blocos de cristais fcados no centro do FOV do sistema PET. Os valores foram obtidos calculando-se as médias nos três eixos de coordenadas $(\mathrm{x}, \mathrm{y}, \mathrm{z})$ para cada posição.

\begin{tabular}{|c|c|c|c|c|c|}
\hline \multirow{2}{*}{$\begin{array}{l}\text { Posições Axiais } \\
\text { (z) }\end{array}$} & \multirow{2}{*}{$\begin{array}{l}\text { Posições transaxiais } \\
(\mathbf{x}, \mathbf{y})\end{array}$} & \multicolumn{2}{|c|}{$\begin{array}{c}\text { FWHM } \\
(\mathbf{m m})\end{array}$} & \multicolumn{2}{|c|}{$\begin{array}{c}\text { FWTM } \\
(\mathbf{m m})\end{array}$} \\
\hline & & Cilindrico & Elíptico & Cilindrico & Elíptico \\
\hline \multirow{3}{*}{ Centro do FOV } & $(0,1)$ & 6,61 & 7,63 & 26,34 & 28,88 \\
\hline & $(0,10)$ & 12,40 & 23,62 & 67,80 & 105,44 \\
\hline & $(10,0)$ & 13,07 & $* 12,00$ & 66,54 & $* 60,27$ \\
\hline \multirow{3}{*}{$1 / 4$ do FOV } & $(0,1)$ & 6,36 & 7,22 & 25,48 & 83,16 \\
\hline & $(0,10)$ & 10,48 & 19,53 & 49,03 & 77,46 \\
\hline & $(10,0)$ & 11,19 & $* 10,14$ & 48,92 & $* 44,14$ \\
\hline
\end{tabular}

Tabela 14: Resultado da resolução espacial para os sistemas PET cilíndrico e elíptico, onde alguns blocos foram reposicionados.

\subsection{Fração de Espalhamento e NEC}

A fração de espalhamento, na geometria elíptica foi de $35,5 \%$, enquanto na geometria circular foi de $34,6 \%$.

A Figura 25 mostra a curva NEC para ambas as geometrias. Para o sistema PET, com geometria elíptica, o pico máximo da curva NEC é atingido para uma taxa de contagem de $239,1 \mathrm{kcps}$ a uma concentração de atividade de $24,8 \mathrm{kBq} \mathrm{ml}^{-1}$. Já na geometria circular, o pico máximo da curva NEC é atingido a uma taxa de contagem de 259,3 kcps a uma concentração de atividade de $34,1 \mathrm{kBq} \mathrm{ml}^{-1}$. 


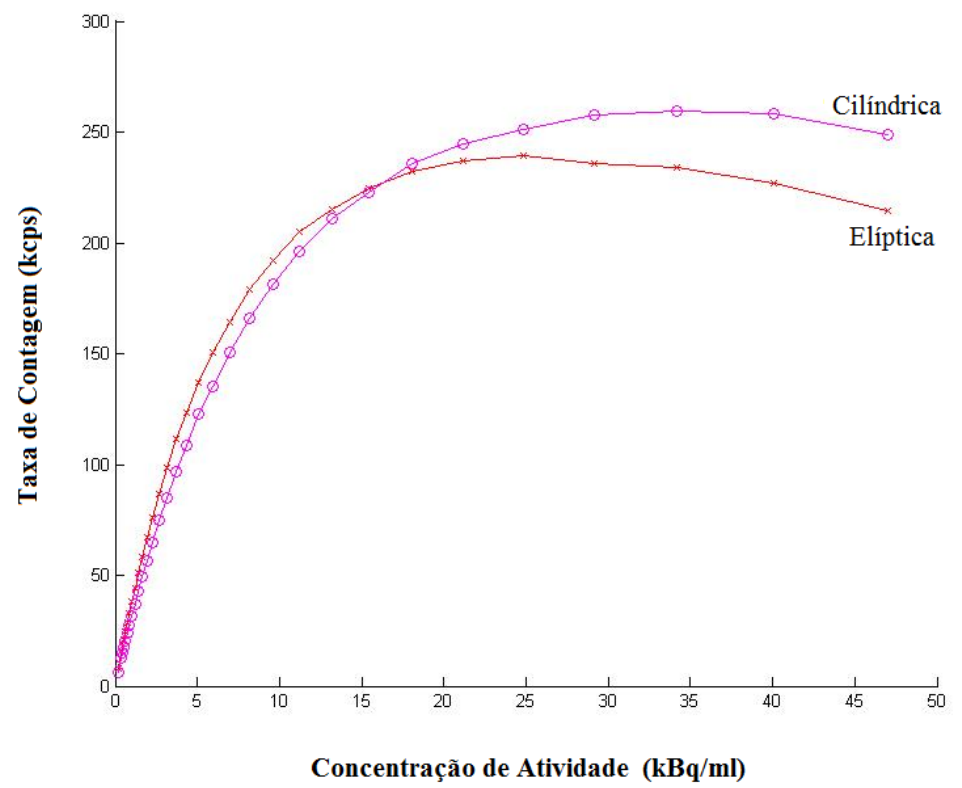

Figura 25: Comparação das curvas NEC para ambas as geometrias propostas. A curva rosa representa o sistema PET em geometria convencional e a curva vermelha representa o sistema PET em geometria diferenciada. 


\section{$\underline{\text { 5. Discussões }}$}

A geometria convencional, com os blocos de cristais arranjados em forma circular, foi construída sem maiores problemas, uma vez que elaborado o primeiro bloco de cristais, o GATE possibilitou replicar este volume em torno de todo o anel através do generic repeater.

Já a geometria elíptica, proposta neste projeto, não foi possível replicar o bloco de cristal de forma direta, como realizado anteriormente para a geometria cilíndrica. Embora o manual do GATE especifique algumas geometrias possíveis para arranjo dos blocos de cristais, entre elas a elipse, foi necessário a utilização do generic repeater e do placement para posicionar e angular os blocos de cristais, um a um, para então formar a geometria desejada. Desta forma, há indícios que o GATE ainda tem parte de seu código em aberto para adequações, entre outras coisas, na montagem de geometrias diferenciadas, já que outros arranjos geométricos dos blocos de cristais podem possibilitar um melhor desempenho dos sistemas PET.

Durante o processo de construção das geometrias propostas neste trabalho, pode-se notar também que o manual da versão utilizada do GATE apresenta alguns erros em suas linhas de comando, pois alguns destes comandos seguem o manual da versão anterior, o que gerou erros iniciais que posteriormente foram corrigidos.

A blindagem dos sistemas em questão se faz necessária para impedir interferências de radiação externa, que poderia alterar os resultados obtidos, e que de fato existem nos sistemas originais.

Uma vez realizadas as simulações para as geometrias cilíndrica e elíptica, observou-se que para o sistema elíptico, as saídas de coincidências não tinham qualquer informação. Desta forma, viu-se que este sistema não gerava as coincidências que posteriormente seriam usadas para elaboração dos sinogramas. Assim houve a necessidade da criação das coincidências, a partir dos singles como descrito na seção 2.4., o que foi realizado no programa ROOT. A fim de garantir as mesmas condições para as duas geometrias, também criou-se as coincidências, a partir dos singles, para o sistema PET cilíndrico.Além disto, é sabido haver um erro no processador de coincidências do GATE, quando escolhido a opção de aceitar todas as multicoincidências e permitindo que todos os singles abram uma janela de coincidência[17]. Esta é a configuração mais utilizada atualmente nos sistemas comerciais, por favorecerem uma maior sensibilidade, embora aumente a contagem de eventos aleatórios. Isto no GATE é 
obtido quando selecionado o processador de coincidências takeallgoods com o parâmetro allPulseOpenCoincGate configurado como "1", ou seja, ativado.

A sensibilidade do sistema elíptico teve um aumento significativo em relação ao sistema cilíndrico. Para o phantom localizado no centro do FOV, o aumento foi de $28,7 \%$ e para o phantom localizado à $10 \mathrm{~cm}$ do centro do FOV o aumento foi de $26,2 \%$. Esse aumento de sensibilidade é devido ao aumento do ângulo sólido coberto por cada detector, causado pela aproximação dos blocos de cristais, o que aumenta a detecção de coincidências.

A resolução espacial, para geometria elíptica apresentou uma piora considerável. De forma geral, para todos os pontos avaliados, a resolução da geometria cilíndrica foi superior, tanto à meia altura (FHWM) quanto à $10 \%$ do pico (FWTM). De acordo com os resultados apresentados na Tabela 10, a única melhora, de resolução no sistema elíptico, deu-se na FWTM, do ponto onde o phantom está deslocado à $1 / 4$ do FOV, com x $=10 \mathrm{~cm}$ e y $=0$.

A degradação da resolução espacial, no sistema PET de geometria elíptica, deu-se, principalmente, devido ao efeito da profundidade de interação. Embora a inclinação dos blocos de cristais tenham sido ligeiramente menores, no sistema elíptico, e que desta forma esperava-se uma menor largura aparente e, consequentemente, melhor resolução espacial, principalmente para os blocos na horizontal, os resultados mostraram que a resolução, para o sistema diferenciado foi inferior.

Buscando melhorar a resolução espacial, criou-se o segundo sistema elíptico, no qual os detectores passaram a ser posicionados com suas faces voltadas para o centro do FOV do tomógrafo. Embora obteve-se melhorias para algumas posições, quando comparados ao primeiro sistema elíptico, no qual os detectores foram posicionados tangentes à elípse, a resolução espacial deste sistema, com geometria elipsoidal também foi inferior comparados ao sistema cilíndrico. De acordo com os resultados apresentados na Tabela 14 houve melhoras, de resolução no sistema elíptico, na FWTM e na FWTM do ponto onde o phantom está no centro do FOV e deslocado à $1 / 4$ do FOV, com $x=10 \mathrm{~cm}$ e y $=0$.

Ao observarmos o sistema PET cilíndrico, todos os detectores tem suas faces voltadas para o centro do FOV, logo para cada detector, há outro oposto a ele no qual, a largura aparente, para estes eventos entre blocos exatamente opostos é igual a largura do detector. Para o sistema elíptico, os detectores mais afastados do centro do FOV, tem suas faces voltadas para o foco da elipse e não para o centro do sistema. Desta forma, para estes 
detectores afastados do centro, não há detectores opostos que estejam face a face um do outro. Portanto, ao considerar uma linha de resposta entre dois detectores opostos no sistema elíptico, estes apresentam uma largura aparente maior do que a largura do detector, degradando a resolução espacial.

A fração de espalhamento, para ambas as geometrias apresentaram valores muito próximos. Porém, fração de espalhamento, do sistema elíptico foi ligeiramente maior, o que é esperado devido a aproximação dos detectores.

No sistema PET cilíndrico, a curva NEC teve o pico máximo em 259,3 kcps a uma concentração de atividade de $34,1 \mathrm{kBq} \mathrm{ml}^{-1}$. No sistema elíptico, o pico máximo é atingido em $239,1 \mathrm{kcps}$ a uma concentração de atividade de $24,8 \mathrm{kBq} \mathrm{ml}^{-1}$. Neste caso, a taxa de contagem, no sistema cilíndrico foi superior em 7,8\%, mas a concentração de atividade, no sistema elíptico foi $27,3 \%$ menor. Isso significa que o sistema PET elíptico atinge seu melhor desempenho em uma concentração de atividade menor comparado ao sistema cilíndrico.

Embora a taxa de contagem para geometria diferenciada seja um pouco menor, a redução da concentração de atividade é mais significativa. Uma vez que a curva NEC atinge o pico no momento em que a curva de coincidências verdadeiras já está chegando em seu limite, tendendo a diminuir após este ponto devido aos efeitos de tempo morto, neste mesmo ponto (pico da curva NEC), as taxas de contagens de eventos aleatórios, que já vem crescendo de maneira mais acentuada e começa a se sobressair em relação as coincidências verdadeiras, como pode ser visto na Figura 15. Desta forma, para valores de atividades maiores, que ultrapassem o pico da curva NEC, aumenta-se o ruído da imagem em consequência deste aumento de coincidências aleatórias e da diminuição das coincidências verdadeiras que são detectadas no sistema. 


\section{Conclusões}

A geometria elíptica, apresenta algumas vantagens em relação a geometria cilíndrica e melhor desempenho para alguns testes realizados, tais como sensibilidade e NEC.

Com respeito a geometria, o sistema elíptico possibilita reduzir o número de blocos de cristais. Pode-se montar este novo sistema reduzindo-se 10 blocos de cristais, o que deve gerar uma redução no custo de fabricação do tomógrafo e consequentemente, possibilitar que este equipamento chegue ao mercado com um valor menor do que os atuais sistemas existentes.

A geometria proposta apresenta uma melhora significativa na sensibilidade, tanto no teste realizado com o phantom no centro do sistema, quanto para o teste realizado com o phantom deslocado a $10 \mathrm{~cm}$ do centro do FOV. O aumento na sensibilidade reflete no aumento na capacidade do tomógrafo detectar coincidências.

O principal ponto negativo, do sistema PET com geometria elíptica, deu-se em relação a resolução espacial, onde houve uma piora significativa comparado ao sistema cilíndrico. Tanto a FWHM quanto a FWTM apresentaram valores maiores comparados ao sistema atual e para a resolução espacial, quanto menor os valores de FWHM e FWTM, melhor é a resolução do sistema em questão. A única melhora deu-se quando a fonte estava localizada mais próxima ao foco da elipse.

Ao realizar os testes de resolução espacial, para o sistema elíptico, com os detectores focados para o centro do FOV do PET, observou-se que não houve alterações significativas nos resultados obtidos quando comparados ao sitema cilíndrico, que de forma geral continuou apresentando melhores valores.

Desta forma, torna-se necessário realizar alguns ajustes na elipse de tal forma a posicionar os blocos de cristais para que os mesmos fiquem direcionados para o centro do FOV do sistema e realizar o ajuste da posição destes blocos com objetivo de diminuir o efeito da DOI para sistemas elípticos. Espera-se com isso obter um ganho na resolução espacial para que assim, tenham valores, no mínimo mais próximos aos encontrados no sistema cilíndrico.

Para a fração de espalhamento, os valores encontrados foram muito próximos tendo o sistema elíptico um valor ligeiramente maior. 
Para o teste NEC observou-se que, embora a taxa de contagem, do sistema elíptico tenha sido um pouco inferior, este sistema apresentou redução na concentração da atividade na qual o tomógrafo apresenta melhor desempenho, possibilitando, desta forma, reduzir a dose de radiação injetada ao paciente, diminuindo potenciais riscos ao realizar o exame. Isto também torna possível diminuir o tempo de cada exame, ocasionando uma maior quantidade de exames ao longo do dia, tornando possível que mais pessoas realizem o exame no mesmo intervalo de tempo. Esta redução na dose de radiofármacos administrados no paciente pode também diminuir o valor do exame e, talvez, possibilitar que mais pacientes submetam-se a este procedimento quando necessários. 


\section{$\underline{\text { 7. Perspectivas Futuras }}$}

- Realizar adequações no posicionamento dos blocos de cristais, no sistema PET elíptico com o objetivo de melhorar a resolução espacial;

- Explorar novas geometrias de sistemas PET, além das geometrias propostas neste trabalho e avaliar seu desempenho.

- Realizar as modificações no código de obtenção das coincidências de acordo com a geometria desejada;

- Fazer as devidas adequações para a montagem dos sinogramas em diferentes geometrias e, também, do sinograma do sistema PET elíptico com as devidas modificações no posicionamento dos blocos de cristais.

- Explorar diferentes processos de reconstruções de imagens para sistemas PET, com blocos de cristais arranjados em diferentes geometrias; 


\section{Referências Bibliográficas}

[1] S. R. Cherry, J. A. Sorenson, and M. E. Phelps, Physics in Nuclear Medicine, Fourth Edi. Philadelphia, 2012, pp. 307-343.

[2] J. K. Poon, M. L. Dahlbom, W. W. Moses, K. Balakrishnan, W. Wang, S. R. Cherry, and R. D. Badawi, "Optimal whole-body PET scanner configurations for different volumes of LSO scintillator: a simulation study.," Phys. Med. Biol., vol. 57, no. 13, pp. 4077-94, Jul. 2012.

[3] V. C. Spanoudaki, F. W. Y. Lau, a. Vandenbroucke, and C. S. Levin, "Physical effects of mechanical design parameters on photon sensitivity and spatial resolution performance of a breast-dedicated PET system," Med. Phys., vol. 37, no. 11, p. 5838, 2010.

[4] M. Bocher, I. M. Blevis, L. Tsukerman, Y. Shrem, G. Kovalski, and L. Volokh, "A fast cardiac gamma camera with dynamic SPECT capabilities: design, system validation and future potential.," Eur. J. Nucl. Med. Mol. Imaging, vol. 37, no. 10, pp. 1887-902, Oct. 2010.

[5] S. Jan, G. Santin, D. Strul, S. Staelens, and K. Assi, "My IOPscience GATE : a simulation toolkit for PET and SPECT," vol. 4543.

[6] “Geant4 Home Page." [Online]. Available: <http://geant4.web.cern.ch/geant4/>.

[7] F. Lamare, a Turzo, Y. Bizais, C. C. Le Rest, and D. Visvikis, "Validation of a Monte Carlo simulation of the Philips Allegro/GEMINI PET systems using GATE.," Phys. Med. Biol., vol. 51, no. 4, pp. 943-62, Feb. 2006.

[8] NEMA NU 2-2007, Performance measurements of positron emission tomography. 2007.

[9] S. R. Cherry, J. A. Sorenson, and M. E. Phelps, Physics in Nuclear Medicine, Fourth Edi. Philadelphia, 2012, pp. 25-26.

[10] R. Eisberg and R. Resnick, Física Quântica. Rio de Janeiro, 1979, p. 72.

[11] P. Zanzonico, "Positron emission tomography: a review of basic principles, scanner design and performance, and current systems," Semin. Nucl. Med., vol. 34, no. 2, pp. 87-111, Apr. 2004.

[12] J. L. Herraiz, S. España, E. Vicente, J. J. Vaquero, M. Desco, and J. M. Udías, "Optimal and Robust PET Data Sinogram Restoration Based on the Response of the System," pp. 34043407, 2006.

[13] B. W. Jakoby, Y. Bercier, M. Conti, M. E. Casey, B. Bendriem, and D. W. Townsend, "Physical and clinical performance of the mCT time-of-flight PET/CT scanner.," Phys. Med. Biol., vol. 56, no. 8, pp. 2375-89, Apr. 2011.

[14] D. L. Bailey, D. W. Townsend, P. E. Valk, and M. N. Maisey, Positron Emission Tomography. pp. 41-82.

[15] L. Angeles, "Measuring PET scanner sensitivity: relating countrates to image signal-to-noise ratios using noise e - Nuclear Science, IEEE Transactions on," vol. 37, no. 2, pp. 783-788, 1990. 
[16] D. L. Bailey, T. Jones, and T. J. Spinks, "A method for measuring the absolute sensitivity of positron emission tomographic scanners," pp. 374-379, 1991.

[17] E. R. Moraes, J. K. Poon, K. Balakrishnan, W. Wang, and R. D. Badawi, "Towards componentbased validation of GATE : Aspects of the Coincidence Processor." Em análise para publicação. 